


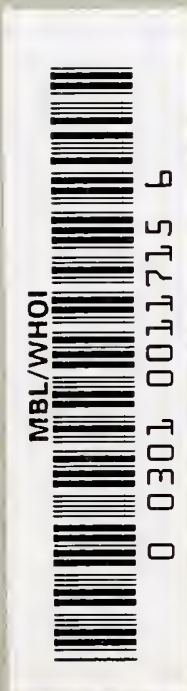





\section{Äussere Einflïsse}

als

\section{Entwicklungsreize.}

August Weismann,

Professor in Freibura i. Br.

Jena.

Verlag von Gustav. Fischer. 1894. 
$49=-1$

10666 


\section{Vorwort.}

Der vorliegende Aufsatz verdankt seine Entstehung der Aufforderung der Universität Oxford, die seit cinigen Jahren dureh Stiftung begründete "Romanes-Lecture" für dieses Mal zu halten. Ich habe dieser Aufforderung um so liebcr entsprochen, als sie mir Gelegenheit bot, meine Auffassung gewisser biologischer Erscheinungen näher zu begriinden, welche gerade ron hervorragender englischer Seite, nämlich durch Herbert Spencer, wiederholt und hartnäckig bekämpft worden war. Ich stütze mich dabei nicht nur auf die schon bekannten, sondern auch auf eine Reihe neuer Thatsachen, welche sich mir aus Versuchen ergebcn haben, die zwar sehon früher angestellt, bisher aber wcder veröffentlicht, noch auch sonst verwerthet worden waren. Ich hoffe, sie später ausfiuhrlich mittheilen zu können; für dic Beurtheilung ihres beweisenden Werthes dürfte genügen, was hier gesagt werden konnte.

Den Titel mciner Schrift hätte ich gern etwas cnger cingeschränkt, es gelang mir aber nicht, olne ihn zugleich 
allzu schwerfällig zu machen. Nicht die ganze grosse Frage von der Rolle, welche die äusseren Einflüsse als Reize bei der Umgestaltung der lebenden Substanz spielen, soll hier zur Sprache kommen, sondern nur ein Theil von ihr: die Verwendung des Reizes als A uslösung verschiedener Entwickelungsanlagen. Um diese Art der Wirkung äusserer Einflüsse in ihrer Bedeutung hervortreten zu lassen, musste allerdings nach manchen Richtungen hin etwas weiter ausgegriffen werden.

Während der Correctur erhielt ich durch die Guite des Herrn Verlegers eine soeben erscheinende Schrift von Oscar Hertwig, "Präformation oder Epigenese?", Jena 1894. Der Verfasser wendet sich darin gegen meine präformistische Vererbungstheorie, indem er geltend macht, dass ich allzuviel auf vorgebildete Anlagen des Keimes bezöge und den bedeutsamen Einfluss der äusseren Bedingungen iibersehe. Es ist hier nicht der Ort, anf die alte und tiefgehende Streifrage nach den Ursachen der Entwickelung einzugehen, doch dürfte mein Gegner aus der vorliegenden Schrift die Ueberzeugung gewinnen, dass auch ich für den Einfluss der äusseren Bedingungen nicht ganz blind bin. Wenn er sich im Speciellen im Anschluss an Spencer auf die staatenbildenden Insecten beruft, so wird ihm dieser Vortrag weiterhin zeigen, dass die Spencer'sche Betrachtungsweise bei den Thatsachen keine Bestätigung findet, und ich hätte in dieser Beziehung meinen Ausführungen, wie sie bereits im Drucke begriffen sind, kein Wort hinzuzusetzen. Da er indessen eines der Spencer'schen Argumente in Bezug auf die Arbeiterinnen der Ameisen als besonders schlagend sich aneignet, welches ich Spencer gegeniiber unbeantwortet gelassen hatte, weil es mir - 
wie so manche Wendung dieses vielgewandten Fechters mehr auf das grosse Publikum berechnet zu sein schien, so habe ich den füfzehn "Zusätzen“, welehe dem Texte des Vortrags folgen, noch einen letzten seehzehnten beigegeben, der meine Antwort darauf enthält.

Ich kann dieses Vorwort nicht schliessen, olne ein Wort der Trauer hinzuzufiigen über den plötzliehen und frühen Tod des Stifters der "Romanes-Vorträge". Nachdem George John Romanes noeh am 2. Mai diesem Vortrag persönlieh beigewohnt hatte, starb er ganz plötzlich am 23. Mai, 46 Jahre alt. Nach dem bedenklichen Zustand seiner Gesundheit in den letzten Jahren musste man allerdings fürchten, dass ihm ein langes Leben nieht besehieden sein würde, doeh hat wohl Niemand sein Ende so nahe geglaubt.

Er starb zu frïh für die Wissenschaft, der er noeh Vieles hätte leisten können. Immerhin wird man sagen diurfen, dass wohl Wenige die Lebenszeit, die ihnen vom Schieksal gegönnt war, besser ausgenutzt haben, wie er. Unermüdlich war er an der Arbeit, und seine feine Beobaehtungsgabe, sein scharfer, kritiseher Verstand und eine grosse Leiehtigkeit der Produetion liessen ihn eine ganze lieihe werthvoller Werke hervorbringen. Noeh im letzten Monat seines Lebens hat er sieh bemüht, zur Klärung einer Frage beizutragen, welehe er selbst sehon vor geraumer Zeit - gewissermaassen vorahnend - zum ersten Mal gestellt hatte, und welehe er jetzt mit steigendem Interesse verfolgte, seitdem sie in den Vordergrund biologischer Forsehung getreten war. So hat seine rastlose Thätigkeit erst mit seinem Leben geendet, und man kann von ihm das Beste sagen, was man von einem hervorragenden Mann 


\section{- VIII -}

sagen kann: er hat die Gaben, mit welchen die Natur ihn ausriistete, voll und ganz zur Entfaltung gebracht.

Freiburg i. Br., 12. Juni 1894.

August Weismann. 


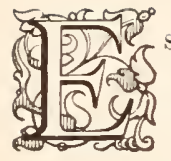

ist mir immer als eine merkwiirdige Idee erschienen, wenn Nägeli sich vorstellte, die Organismenwelt unserer Erde habe sich durch in ihr selbst gelegene innere Triebkräfte entwickelt, und die äufseren Einflïsse hïtten dabei nur in untergeordneter und nebensächlicher Weise mitgewirkt, verbessernd und modifieirend, aber nieht bestimmend. Meinte dieser scharfsinnige Naturforseher doch geradezii, der Gang der Entwicklung: wïrde im Grossen und Ganzen nahezu ebenso ausgefallen sein, wie er es thatsächlich ist, wären auch die Lebensbedingungen von den ältesten Zeiten her sich stets gleich geblieben.

Ieh erwähne diese Ansieht nicht, um sie zu bekämpfen; ieh habe das vor geraumer Zeit sehon gethan, und es wird heute nieht viele Naturforscher mehr geben, die ihr zustimmen. Sie ist gewissermassen ein letzter Versueh gewesen, noch einen Rest der verlassenen Sehöpfungshypothese $z u$ retten, indem man eine treibende Kraft in die Organismen lineinlegte, anstatt ihre Entwieklung aus dem Ineinanderspiel der äusseren und inneren Kräfte abzuleiten, aus der Einwirkung der Aussenwelt auf den Organismus.

Es ist schwer, nicht an die Führung der äusseren Einflüsse zu glauben, wenn man sieht, wie die ganzen Lebens- 
äusserungen der Thiere und Pflanzen in letzter Instanz immer Reactionen auf äussere Einflüsse sind, wie Thicr und Pflanze Maschinen vergleichbar sind, derart gebaut, dass sie auf die Reize der Aussenwelt hin aufs Zweckmässigste für ihre Selbsterhaltung arbeiten müssen. Da sie doch einmal geworden sind, wie sollten sie anders zu cinem so wunderbaren Grad der Anpassung an diese Reize gekommen sein, wenn diese nicht selbst dabei in irgend ciner Wcise mitgespielt hätten? Da aber jede Lebensäusserung eine Reaction auf Reize ist, so bleibt für eine Entwicklungskraft kaum noch Etwas zu thun übrig.

Wenn wir aber auch heute wohl berechtigt sind, eine Entwicklung aus rein inneren Ursachen abzulehnen, so kann doch keinesweg's behauptet werden, dass wir über die Artt und Weisc, wie die äusseren Einflüsse die Organismen gestalten und umgestalten, schon zu voller Sicherheit gelangt wären. Entgegengesetzte Ansichten bekämpfen sich noch, und in wichtigen Punkten herrscht die Unklarheit.

Ich möchte heute Ihre Aufmerksamkeit auf einen solchen Punkt richten.

Es wird oft ohne viele Prüfung angenommen, diesc oder jene Veränderung an einem lebenden Wesen sei die dircete Folge einer äusseren Einwirkung; der Ausspruch scheint auch richtig, insofern die betreffende Veränderung wirklich in Causalnexus mit einer bestimmten äusseren Finwirkung steht, und dennoch liegt der Annahme eine völlig unrichtige Meinung über den Zusammenhang der Erscheinungen zu Grunde. Für viele Fälle wird man das ohne Weiteres zugeben. Wenn z. B. Jemand behaupten wollte, dass die Kältc die wirkliche Ursache des Winterschlafes der Murmelthiere sei, so wäre das eine schr unvollständige Erkenntniss, denn nicht 
die Kälte, sondern die eigenthümliche Organisation des Murmelthieres bedingt die Reaction des Winterschlafes, und die Kältc ist nicht im Stande, einen Hund oder einen Vogel in Winterschlaf zu versetzen. Es liegt also hier eine specielle Anpassung des Organismus des Murmelthieres an einen Reiz, die Kälte, vor, der dasselbe in regelmässigen Perioden trifft, und dessen sonst verderblicher Wirkung der Organismus sich auf diese Weise entzieht. Wir können die feinsten "molekülaren" Veränderungen im Nervensystem, auf welchen die Fähigkeit zum Winterschlaf beruhen wird, nicht mit dem Mikroskop nachweisen, aber irgend eine Anpassung der Art muss da sein, und sie kann unmöglich als einc d i r c c te W ir kung der Kälte angesehen werden, sondern im Gegentheil als eine Einrichtung zur Begegnung der Kälte, deren Entstehung nur auf Selectionsprocessc bezogen werden kann. Aehnlich verhält es sich in tausend andcren Fällen. Wenn die Mimosa pudica ihre Blätter auf Beriihrung neigt und zusammenklappt, so spielt die Berïhrung dabei nur die Rolle des auslösenden Reizes; die eigentliche Ursache aber der Bewegung liegt im cigenthümlichen Bau der Pflanze. Wir vermögen auch - besonders seit den Beubachtungen von Stahl und Haberlandt - deutlich den Nutzen zu erkennen, der den zarten Blättern aus ihrer Reizempfindlichkeit erwächst, indem sie der Wucht der fallenden Tropfen eines tropischen Regengusses dadurch einigermassen ausweichen können, dass sie denselben nur die Kante ihrer Blättchen darbieten ${ }^{1}$ ).

Aber die modernc Pflanzen-Physiologie hat den Beweis erbracht, dass auch viel allgemeinere Erscheinungen des

1) Siehe: Zusatz 1. 
Pflanzenlebens auf Anpassung beruhen müssen, und nicht nur einfach eine Folge der allgemeinen Pflanzennatur sind. Ich bekenne gern, dass es mich jedesmal in bewunderndes Erstaunen versetzt, wenn ich sehe, bis zu welchem Grade der Sicherheit und Klarheit die Analyse der Reactionen des Pflanzenkörpers auf äussere Reize heute gediehen ist. Die Wirkung der Schwere bestimmt die Wurzel, senkrecht nach abwärts, den Stamm aber "senkrecht nach oben zu wachsen". Diese "geotropische" Empfindlichkeit der Pflanze ist eine so feine, dass selbst auf dem schwankenden Boden horizontal im Wasser flottirender Triebe der Utricularia der Blüthenschaft 4-5 Centimeter hoch genau senkrecht emporwächst, so genau, dass er gerade stehen bleibt und seine Blumen zur Entfaltung bringt, während er doch umstiirzen und ins Wasser fallen müsste, wenn er auch nur Weniges nach einer Seite ïberneigte.

Und wie überaus wichtige Folgen hat die Empfindlichkeit der Pflanze gegen die Einwirkung des Lichtes. Wie unendlich fein abgestuft ist die Reactionsweise der Pflanzentheile in dieser Hinsicht, und wie genau angepasst den Bedürfnissen der Pflanze. Gerade beim Licht könnte ein oberflächlicher Beobachter meinen, man habe es hier nicht mit Anpassungen zu thun, sondern mit einer Grundeigenschaft der Pflanze, und das wäre auch insoweit richtig, als Pflanzen ohne alle Reizbarkeit für Licht wohl nicht denkbar sind ${ }^{1}$ ). Aber die Art und Teise, wie eine Pflanze, oder ein Pflanzentheil auf Licht reagirt, ist bekanntlich ungemein verschieden, und diese Modificationen der Lichtempfindlichkeit beruhen auf Verschiedenheiten des feinsten "molekülaren" Baues der Pflanze; wenigstens ist man nicht

1) Siehe: Zusatz 2. 
im Stande gewesen, ihren Grund in den gröberen, direct wahrnehmbaren Bauverhältnissen der Zellenzusammenfügung zu erkennen. Wenn die Sprosse der meisten Pflanzen zwar sich dem Lichte zukrümmen oder positiv heliotropisch sind, andere aber, wic die Klettersprosse des Epheus und des Kürbis, vom Lichte wegstreben, negativ heliotropisch sind, so kann dicse Verschicdenheit nur auf Verschiedenheiten der Pflanzensubstanz beruhen, und da diesclben zugleich liöchst zweckmässig sind, indem sie in einem Falle die Pflanze in den Stand setzen, das Licht möglichst auszunutzen, im anderen Falle aber, zu klettern, so können wir sie nur als Anpassungen bczeichnen und haben wieder keine andere Erklärung für ihr Zustandekommen, als Selection.

In allen diesen Fällen handelt es sich um ererbte Structuren des Organismus und Einrichtungen, dic unter den gewöhnlichen Lebens- und Wachsthumsbedingungen der Pflanze immer in derselben Weise zur Entwicklung gelangen, und die ihrerseits dann es bedingen, dass die Pflanze auf äussere Reize in richtiger, d. h. zweckmässiger Weisc antwortet.

Ganz Aelnliches spiclt auch im Organismus der Thiere eine bedeutsame Rolle. Der Anatom Hermann Meyer hat wohl zuerst auf jene bis ins Kleinste gehende Zwcckmässigkeit der thicrischen Gewebe aufmerksam gemacht, wie sie am auffallendsten in der Architektur der schwammigen Substanz der Röhrenknochen bei den höhcren Wirbelthieren uns entgegentritt. Die Spongiosa der Knochen ist nach dem technischen Princip der Gewölbestructur gebildet, indem sie sich aus zahlreichen feinen Knochenbälkchen zusammensetzt, die alle in der Richtung des stärksten Druckes und Zuges liegen, also so angeordnet sind, wie es geschehen musste, wenn die höchste Festigkeit 
bei dem geringsten Materialverbrauch erreicht werden sollte. Nun ist aber die Richtung, Stellung und Stärke dieser Knochenbälkchen nicht etwa schon im Voraus bestimmt und angeboren, sondern sie richtet sich nach den Umständen. Wird der Knochen gebrochen und heilt schief wieder zusammen, so ordnen sich die Spongiosabälkchen in nener Weise an, und zwar wieder so, dass sie in die nun veränderte Richtung des stärksten Druckes und Zuges zu liegen kommen. Sie vermögen sich also den neuen Verhältnissen anzupassen.

Ein ursächliches Verständniss dieser wunderbaren feinsten Anpassungen verdanken wir erst Wilhelm $\mathrm{Roux}^{1}$ ). $\mathrm{Er}$ erklärte das Zustandekommen derselben durch Uebertragung des Princips der Selection auf die Theile des Organismus. Wie zwischen den Individuen einer Art ein Kampf um das Ueberleben stattfindet, aus welchem der Bestangepasste als Sieger hervorgeht, so kämpfen auch die kleinsten Lebenstheilchen miteinander, und wem es am besten gelingt, Nahrung und Raum sich zu sichern, der wächst und vermehrt sich am schnellsten und verdrängt so die minder gut Ausgeriisteten. In dieser Weise müssen Selectionsprocesse innerhalb des Organismus an jeder Kategorie von Einheiten sich abspielen, an den kleinsten Lebenstheilchen sowohl (den Biophoren), als an Zellen und an Geweben. Ueberall kïmpfen gleichwerthige Theile miteinander, und überall siegen die besten. Man könnte diese Vorgänge als "Intra-Individual-Selection" oder kurz als "Intraselection" bezeichnen.

Es kann nicht meine Aufgabe sein, Ihnen den ganzen

1) Wilhelm Roux, "Der Kampf der Theile im Organismus". Leipzig 1881. 
Gedankengang von Roux ausführlich darzulegen, ich darf ihn vielmehr als bekannt annehmen: aber Eines möchte ich doch nicht unerwähnt lassen, worin nämlich nach $\mathrm{R} o \mathrm{ux}$ die Ueberlegenheit des einen Theilchens über das andere und damit die Möglichkeit eines Kampfes beruht. Es ist die schwächere oder stärkere Reaction auf einen bestimmten Reiz und die Thatsache, dass der functionelle Reiz ein Organ kräftigt. Wie die Contraction den Muskel kräftigt, so wird auch jedes andere histologische Element durch den specifischen Reiz, auf welchen es eingerichtet ist, stärker crnährt. Die verschiedene Empfänglichkeit für specifische Reize vertritt also hier die Stelle der verschicdenartigen Vorzüge, welche beim Kampf der Individuen den Sieg verleihen können. Wo immer im Organismus ein bestimmter Reiz einwirkt, da müssen sich gerade diejenigen Elemente vermehren, welche von diesem Rciz am stärksten getroffen und in Thätigkeit gesetzt werden. Elemente also, wclche durch Zug und Druck zum Wachsthum und zur Vermehrung angeregt werden, müssen sich an den Stellen anbäufen und in den Richtungen anordnen, in welchen Zug und Druck auf sie am stärksten einwirken. So erklärt sich die Spongiosastructur der Knochen und die vielfachen Kreuzungen der Bindegewebszüge in der Delphinflosse, so auch die wunderbar zweckmässige Gestalt und Richtung der Blutgefässäste; so erklären sich iiberhaupt alle die einzelsten und feinsten Zweckmässigkeiten der Gewebe bei höheren Thieren, insofern sie alle die Fähigkeit haben, sich den Umständen, welche gerade im Organismus abwalten, anzupassen ${ }^{1}$ ).

Roux ging allerdings noch wciter. Er meinte, dass

1) Siehe: Zusatz 4. 
diesc histologischen Structuren iiberhaupt und ausschliesslich auf Intraselection beruhten, dass sie durch sie allein und nicht durch Personenselection entstanden seien, und darm, glaube ich, war er im Irrthum. Es klingt freilich sehr bestechend, wewn er fragt, wie sollten solche kleine Zweckmässigkeiten wie die Spongiosastructur durch den Kampf der Personen, durch gewöhnliche Naturziichtung entstanden sein? Gesetzt, es träten auch eimmal hier oder da in einem Knochen durch spontane Variation einige Spongiosabälkchen auf, wie sollten sie ihrem Träger irgend eine Ueberlegenheit im Kampf ums Dasein verleihen, wo doch erst Hunderte und Tausende von ihnen den Knochen zweckmässiger machen? Ich möchte aber dagegen fragen, ob es nicht denkbar sein sollte, dass die Grundlage eines durch viele Körpertheile verbreiteten Gewebes gleichzeitig und gleichmässig. vom Keim aus durch Personalsclection verbessert würde? Sollten die Federn der Vögel, die Haare der Säugethierc c in zeln geziichtet worden sein, da doch Intraselection sie unmöglich geschaffen haben kann?

Dieser Irrthum in der genialen Conception Roux's hängt auf's Genaueste mit einer Frage zusammen, deren Bedeutung crst jetzt der Wissenschaft zu vollem Bewusstsein gekommen ist, mit der Frage nach der Vererbung erworbencr Eigenschaften. Zur Zeit, als Roux mit den hier kurz skizzirten Gedanken hervortrat (1881), war man von dieser Erkenntniss noch weit entfernt. Wenn auch Einzelne gelegentlich einen Zweifel daran aussprachen, ob cine derartige Vererbung auch wirklich stattfinde, so hatte man doch den Gedanken nicht weiter verfolgt und war sich nicht bewusst, eine wie tief greifende Umgestaltung alle unsere Vorstellungen iiber die Entwicklung der 
Arten erleiden mussten, wemn es sich herausstellte, dass eine Vererbung erworbener Eigensehaften nicht stattfindet. So wird man Roux keinen Vorwurf daraus machen wollen, dass auch er eine solche Vererbung für möglieh hielt und sich vorstellte, dass die histologischen Anpassungen dureh Intraselection allein geschaffen werden könnten, indem sieh die dureh Uebung eines Gewebes im Einzelleben entstandene zweckmässige Structur auf die folgende Generation vererbe und dam in dieser und den folgenden steigere bis zu möglichst hoher Vollkommenheit. Er legte gerade auf diesen Punkt besonderen Nachdruck, weil er mit Recht sich vorstellte, dass so fein ausgearbeitete Anpassungen nicht mit einem Male entstanden sein könnten, vielmehr nur im Laufe der Generationen, und weil er keinen anderen Weg sah, auf dem dies gesehehen könnte, als den der Vererbung der im Einzelleben durch Intraselection errungenen Anpassungsstufen.

Es gibt aber doch noeh einen anderen Weg, und wenn ieh nicht sehr irre, wird auch Roux diesen heute für den richtigen halten. Nieht die einzelnen zweekmäsigen strueturen werden vererbt, sondern die Qualität des Materials, der Bausteine, aus welehen Intraselection sie in jedem Einzelleben neu wieder aufbaut. Eigensehaften ron Biophoren, von Zellen sind es, welche vererbt werden und welehe sich im Laufe der Generationen immer günstiger und zweekmässiger gestalten können, wenn sie der Naturzüchtung unterliegen. So steigerte sich im Laufe der Generationen die Reizempfindlichkeit für Zug und Druck bei gewissen Zellen der Knochenanlage, und diese bildete dann in jedem Einzelleben die Grundlage für die Proeesse 
der Intraselection. Nicht die einzelnen Spongiosabälkchen vererbten sich, wohl aber eine Zellenmasse, welche vom Keim her auf Zug und Druck so reagirt, dass die Spongiosastructur zu Stande kommen muss. Es ist ganz ähnlich, wie bei der Pflanze, deren geotropische Reizempfindlichkeit die Wurzel zwingt, nach abwärts zu wachsen, den Spross aber nach aufwärts und die Aeste schräg seitwärts; dic Reizempfindlichkeit, der positive oder negative Geotropismus ist ererbt und beruht auf Keimesanlage; die specielle Richtung aber, welche der wachsende Theil einschlägt, wird durch die wechselnden Bedingungen des Einzellebens gegeben; sie wird in jedem Einzelleben neu erworben und kann nicht vererbt werden. Die grosse Bedeutung der Intraselection beruht nicht darauf, dass sie direct vererbbare Bildungen schaffte - dazu ist sie ausser Stande vielmehr darin, dass sie die durch Personenselection hervorgerufenen Keimesanlagen den wechselnden Bedingungen gegeniiber zweckmässig zur Entfaltung bringt. Intraselection bewirkt die Specialanpassung der Gewebc an die speciellen Entwicklungsbedingungen des einzelnen Individums. Wenn ein Baum nach einer Seite dicht von anderen Bäumen umdrängt und vom Lichte abgeschnitten wird, so bleibt er hier im Wachsthum zurïck und entfaltet sich um so üppiger nach der anderen, freien Scite hin; die ererbte, sogenannte "molekülare" Beschaffenheit seiner Sprosse, dic wir als positiven Heliotropismus bezeichnen, zwingt iln dazu; und wenn ein gebrochener Ḱnochen falsch verheilt, so stellen sich die Bälkchen seiner Spongiosa wieder in die Richtung des stärksten Drucks und Zugs - die ererbte "molekülare“ Reizempfindlichkeit der bindegewebigen. Grundlage des 
Knochens zwingt sie dazu. Man kann sagen, Intraselection bewirkt die Anpassung des Individnums an seine zufälligen Entwicklungsbedingungen, die Anpassung seiner ererbten Anlagen an die grerade eintretenden Umstände. Diese Anlagen selbst aber können nicht - wie Roux es vor vierzehn Jahren glaubte - durch Intras election geschaffen werden, sondern nur durch Personalselection. Die Bedeutung des "Kampfes der Theile" scheint mir aber durch diese Erkemntniss nicht vermindert $\mathrm{zu}$ werden; er bleibt auch jetzt noch von der allergrössten Bedeutung, denn ohne ihn wïrde kein zusammengesetzter Organismus bestehen können. Existirte Intraselection nicht, so würden zwar alle die feinsten histologischen Anpassungen auch haben entstehen können, nämlich durch Personalselection, aber ein lebensfähiger Organismus höherer Ordnung hätte damn überhaupt nicht werden können. Denn derselbe würde sich dann vom Ei her aufbauen, etwa wie ein Gebäude, zu dem sämmtliche Steine schon im Voraus behauen worden wären, ehe man weder den Platz kennt, auf dem es sich erleben soll, noch den Gebrauch, zu dem es dienen soll, noch die Umgebung, in die es zu stehen kommt. Eine solche in allen Einzelheiten genau vorherbestimmte Ontogenese wiirde so wenig zu einem lebensfähigen Organismus führen können, als wie Roux sich treffend ausdriickt - "ein Feldherr den Sieg in der Schlacht gewinnen würde, der statt der allgemeinen Befehle an die Generäle über die Aufstellung und Verwendung der Truppen, von vornherein Specialbefehle bis herab zu den Thaten des Lieutenants oder des einzelnen Mannes geben wollte". Die Einflüsse, welche den sich aufbauenden Organismus treffen, sind niemals völlig 
gleiche, und so muss er eine gewisse Freiheit besitzen, sich ihnen anzupassen.

Diese Einfliisse sind auch keineswegs blos äussere, sondern in ausgiebigem Maasse auch solche, die von einem Theil des Organismus auf den andern ausgeübt werden, von Zelle auf Zelle, von Gewebe auf Gewebe, von Organ auf Organ. Was Darwin als Correlation bezeichnete und mit Recht als einen wichtigen Factor der Entwicklung ansah, das ist, wenn ich nicht irre, zum grössten Theil eine Wirkung der Intraselection, und diese spielt dabei nicht nur in der Ontogenese, sondern anch in der Phylogenese eine bedeutsame Rolle, obwohl ihre Resultate nicht vererbt werden.

Bei dem oft schon benuitzten Beispiel einer Hirschart, deren Geweih aus irgend einem Grund in aufsteigender Entwicklung begriffen ist, wird der Kopf im Laufe der Generationen immer stärker belastet, und man hat nun gefragt, wie es denn möglich sei, dass diejenigen Körpertheile, welche dieses Gewicht zu tragen und zu bewegen haben, sich alle gleichzeitig und in Harmonie mit einander verändern könnten, falls diese Veränderungen durch Selectionsprocesse erfolgen miissten, und nicht dum Vererbung der Wirkungen von Gebrauch oder Nichtgebrauch. Diese von Herbert Spencer ${ }^{1}$ ) aufgeworfene Frage der Coadaptation erhält ihre Antwort durch den Vorgang der Intraselection. Es ist gar nicht nöthig, dass alle

1) Herbert Spencer, „Die Factoren der organischen Entwicklung" in "Kosmos", Jahrgang 1886, Bd. I, p. 241 u. 321 und:

Derselbe: „Die Unzulänglichkeit der natiurlichen Zuchtwahl" in "Biolog. Centralblatt", Bd. XII, 1893, p. 696, 705 und 737. 


\section{$-13-$}

diese Theile, der Schädel, die Muskeln und Bänder des Nackens, die Halswirbel, die Knochen der Vorderbeine u. s. w. alle gleichzeitig durch Keimesvariationen der Vergrösserung des Geweihes nachfolgen, denn einstweilen wird in jedem einzelnen Individuum die nöthige Anpassung durch Intraselection bewirkt, durch den Kampf der Theile unter Führung der trophischen Wirkung des functionellen Reizes.

Wohl vererbt sich die auf diese Weise erworbene Verstärkung der betreffenden Theile nicht, aber sie macht es möglich, dass die primäre Abänderung erhalten bleibt, dass die vortheilhafte Variation des grösseren Geweihes - eine solche einmal angenommen - nicht zum Untergang ihres Besitzers dadurch führt, dass seine iibrigen Theile nicht nachfolgen können. Alle Theile des Organismus sind in einem gewissen Maasse veränderlich und bestimmbar durch das Maass und die Natur der Reize, die auf sie einwirken, und diese Fähigkeit, auf functionellen Reiz zweckmässig zu antworten, muss als das Mittel betrachtet werden, welches es ermöglicht, bei der phyletischen Umgestaltung einer Art die harmonische Zusammenpassung der Theile beizubehalten. Wenn Herbert Spencer meinte, dass in der Harmonie der zusammen und mit einander wirkenden Theile ein zwingender Grund läge für die Annahme einer Vererbung erworbener Eigenschaften, so lat er dabei überschen, dass es ein nie rastendes Princip gibt, welches ununterbrochen im Begriff ist, die Theile, welche mit einander arbeiten, auch in Bezug auf ihre Grösse und Leistungsfähigkeit in Harmonie zu setzen: Intraselection.

Gewiss kann dieselbe nicht jeden Grad der Disharmonie der Theile ausgleichen, denn auch hier wird die 
Anpassungsbreite ihre bestimmten Grenzen haben, und wir wissen ja, dass allzu anhaltende oder heftige Functionirung nicht mehr Stärkung des Organs bewirkt, sondern Schwächung. Da indessen auch die primären Veränderungen der phyletischen Umgestaltung - hier also diejenige des Geweihes - in kleinen Schritten erfolgt, soweit wir sehen, so würden die secundären Anpassungen in den meisten Fällen nachfolgen können. Es wird Zeit gewonnen, sodass im Laufe der Generationen durch stete Selection der am besten zusammenpassenden Keimesanlagen auch eine möglichst hohe Harmonie dieser selbst, und damit eine definitive, auf alle Theile sich beziehende Umwandlung der Art erzielt wird. Die Reductienstheilungen des Keimplasmas und die Mischung der elterlichen Keimplasma-Hälften bei der Befruchtung spielen dabei ohne Zweifel eine bedeutungsvolle und unentbehrliche Rolle, indem sie für die stete Anwesenheit einer Fülle verschiedenster Anlagencombinationen Sorge tragen.

Ich möchte iibrigens glauben, dass eine vollkom men e Harmonie der Ánlagen des Keimes überhaupt niemals zu Stande kommt, in dem Sinne, dass die nachträgliche Anpassung der Theile während des Aufbaues des Organismus entbehrt werden könnte. Dies scheint mir so wenig möglich zu sein, als dass jemals eine absolute Vollkommenheit irgend eines Organs erreicht wiirde. Alle Anpassungen sind nur relativ vollkommen; das liegt, wie mir scheint, im Princip der Selection, welches sie nicht weiter steigern kann als so weit, dass es gerade ausreicht, um die Art lebensfähig zu erhalten. So wird auch die Harmonie der Anlagen, welche im Keimplasma zusammengeordnet sind, niemals grösser werden können, als eben nöthig ist, um 
mit Hülfe der Intraselection ein genügend leistungsfähiges Individuum herzustellen.

Eine völlige Harmonie der Anlagen kann schon deshalb bei geschlechtlich erzeugten Individuen im Keimplasma nie rorhanden scin, weil dasselbe immer aus zwei individuell verschiedenen Hälften zusammengesetzt ist. Wenn wenigstens Diejenigen im Recht sind, welche mit Darwin, Galton, de Vries und mir eine präformistische Zusammensetzung der Keimsubstanz annehmen, eine Keimsubstanz, die aus Anlagen zusammengesetzt ist, so müssen ja bei jeder Befruchtung recht verschiedene Anlagen der entsprechenden Theile vom Vater und ron der Mutter her im Keime zusammentreffen. Meistens sind die fertigen Theile der Eltern so verschieden, dass sie sich nicht abwechselnd an einander setzen liessen, ohne Monstra zu bilden, und somit könnten auch ihre Keimesanlagen sich nicht mit einander verbinden zum Aufbau eines harmoniselien kindlichen Organismus, besässen sie nicht alle eine gewisse Variationsbreite und wären sie nicht dadurch befähigt, sich an einander anzupassen. So wenig wir auch noch in diese geheimnissvollen Vorgänge hincinsehen, so werden wir doch kaum irre gehen, wenn wir hier Verhältnisse zu Grunde licgend denken, welche unter den Begriff der Intraselection fallen. Der Kampf ungleich stärkerer, d. h. ungleich reizempfïnglicher Theile muss es sein, der die Verschmelzung der elterlichen Anlagen zu Stande bringt und der es verhindert, dass Monstra zu Stande kommen, deren Theile nicht zu einander passen.

Intraselection ist offenbar auch das Mittel, welches es möglich macht, dass aus einem nur ungefähr zusammenstimmenden Gebäude von Anlagen, wie es im Keimplasma 
nach meiner Vorstellung beisammen liegt, dennoeh ein harmoniseher, lebensfähiger Organismus sieh aufbauen kann. Die Voraussetzung aber ihrer ganzen Thätigkeit ist immer die speeifisehe Reizempfindlichkeit der einzelnen Anlagen und Einheiten niederer und höherer Gruppen, und diese kamn natïrlieh nur dureh gewöhnliche Selection der Personen auf Grund von Keimesvariationen entstanden sein. Denn sie ist erblich, hier, wie bei den Pflanzen, deren geotropische, heliotropische, anisotropisehe, an isomorphisehe u. s.w. Reizbarkeit ihren ganzen Aufbau beherrseht ${ }^{1}$ ). Alle diese Reaetionen des Organismus auf äussere Einflüsse sind also gewissermassen von langer Hand her vorbereitete, vorgesehene.

Damit soll nicht bestritten werden, dass der Organ is mus auch von Reizen getroffen werden kann, a uf welehe er nieht schon im Voraus eingeriehtet ist. Es sind zahlreiche Beispiele bekannt, in welehen ungewohnte klimatisehe Einwirkungen Veränderungen an Thieren oder Pflanzen hervorgebracht haben. Wenn europäisehen Hunden unter dem Einfluss der indisehen Hitze die Haare ausfallen, so ist das gewiss ein Beweis dafür, dass ihr Organismus eben nieht auf Tropenhitze eingeriehtet ist, und wenn ein kleiner rothgoldener Schmetterling, Polyommatus Phlaeas, einen sehwarzen Anflug erhält, nachdem er sich in wärmeren Gegenden, z. B. in Süditalien, festgesetzt hat, so kann dies wohl ebenfalls nicht als eine Anpassung betraehtet werden, sondern, wie die sehönen Experimente von Merrifield in Uebereinstimmung mit meinen eigenen lehren, muss es als eine

1) Siehe: Zusatz 3 . 
directe Wirkung der Wärme angesehen werden ${ }^{1}$ ). Nan hat in diesem und in manchen ähnlichen Fällen keinen Grund zu der Annahme, dass diese Reactionsweise der Schmetterlings-Schuppen eine gewissermassen beabsichtigte sei, oder genauer gesprochen, dass die Schuppen-Determinanten schon im Voraus durch Naturziichtung so eingerichtet worden wïren, dass sie durch hohe Temperatur schwarz erzeugen miissen.

In anderen, äusserlich ganz ähnlichen Fällen aber könnte es sich so verhalten, wenn es auch im Augenblick noch nicht möglich ist, dariiber bestimmt zu urtheilen. Jedenfalls wird man sich hiiten miissen, nicht olne Weiteres Verïnderungen, welche auf Temperatureinflüsse hin eintreten, immer schon für in diesem Sinne zufällige zu halten. Ich habe ror Jahren Versuche mit dem saisondimorphen sogenannten „Landkïrtchen“, Vanessa Levana-Prorsa, gemacht und komnte damals nachweisen, dass diese beiden in Färbung und Zeichnung sehr verschiedenen Formen ein und derselben Sclmetterlingsart von der Einwirkung verschiedener Wärmemengen während der Puppenperiode ablängen; man kann durch niedere Temperatur die Sommergeneration in die Frïhlingsform verwandeln. Es ist mir indessen damals schon zweifelhaft erschienen, ob eine so totale Umgestaltung der Farbe und Zeichnung, wie sie bei der Sommerform Prorsa eingetreten ist, wirklich nur auf der zufälligen Wirkung höherer Temperatur beruhen kann, und ich habe damals schon den Gedanken an Mimikry im Stillen gehegt, wenn auch als unwahrscheinlich einstweilen wieder verworfen. Nachdem wir aber jetzt durch die ver-

1) Siehe: Zusatz 5 .

Weismann, Reize und Ursachen. 
einten Bemühungen vieler vortrefflicher Beobachter - zuletzt noch Erich Haase's ${ }^{1}$ ) - dic Erscheinung der Mimikry als einc vicl allgemeincre und verbreitetere kennen gelernt haben, als man damals ahnen konnte, möchte ich bestimmter die Möglichkeit in's Auge fassen, dass die Sommerform Prorsa auf Nachahmung der Limenitis Sibylla beruhen könnte, welche mit Prorsa dieselben Flugplätze an lichten Waldstellen gemein hat, und welcher diesc in der That auffallend ähnlich sieht. Einen förmlichen Beweis kam ich freilich dafiur zur Stunde nicht führen, da ich nicht eimmal sagen kann, ob etwa diese Limenitis Sibylla zu den immunen Arten zu rechmen ist. Ich verzichte auch hier auf Darlegung der Gründe, welche miclı zu dieser Vermuthung drängen, und crwähne den ganzen Gedanken nur, um an cinem Bcispiel, sei es num ächt oder blos fictiv, darzuthun, wie der Schein einer Umwandlung durch äusscren Einfluss entstehen könnte, während dicser Einfluss - hier also die Wärme - in Wahrheit doclı nur die Rolle des auslösenden Reizes spielt, und dic eigentliche Ursache in eincr Abänderung der Keimesanlagen beruht, hervorgerufen durch Selectionsprocesse, lier durch Anpassung der Sommergeneration an einc mit ihr zugleich fliegende geschützte Art.

So wäre es auch durchaus nicht undenkbar, dass die Raupen einer Schmetterlingsart, welche zwei Generationen im Jahre hervorbringt, sich in Bezug auf Schutzfärbung an zwei verschiedene und alternirende

1) Dr. Erich Haase, "Untersuchungen iiber die Mimikry auf Grundlage eimes natiirlichen Systems" der Papilioniden. Stuttgart 1893. 
Nahrungspflanzen angepasst hätten, und auch in diesem Falle wiirde der periodische Weehsel der Färbung seheinbar auf dem direeten Einfluss des Sommer- und Herbstklimas beruhen, in Wahrleit aber auf doppelter Keimesanlage, die dureh irgend einen äusseren Reiz nur abweehselnd ausgelöst wüirde, sei dieser ıłun Wärme oder die Qualität des die junge Raupe treffenden Liehtes. Vielleicht stellen die Raupen des nordamerikanischen Falters Lycaena Pseudargiolus einen solchen Fall dar. Nach W. H. Edwards besitzt die Sommer- und Herbstbrut dieses Falter's verschieden gefärbte Raupen; die ersteren sind weiss und gut geschützt auf den weissen Blithenknospen ihrer Nährpflanze, Cimieifuga racemosa, die letzteren haben eine gelbgrüne oder olivengrüne Färbung und leben auf einer viel später blïhenden Pflanze mit gelben Blumen, Aetinomeris squarrosa. Ob auch die letztere Färbung als proteetiv zu betrachten ist, wird nicht ausdrüeklieh gesagt, wie demn überhaupt der Fall erst speeiell auf diesen Gesichtspunkt hin untersucht werden müsste, ehe man ihn mit Sieherheit als zeitliehe Doppelanpassung betraehten darf ${ }^{\mathbf{1}}$ ).

Zeitliche Doppel-Anpassungen kennen wir übrigens schon seit langer Zeit an vielen polaren Säugethieren und Vögeln, nur dass hier die versehriedene Firbung nicht auf zwei suecessive Generationen vertheilt ist, sondern an demselben Individuum naeheinander auftritt. Aueh hier seheint wenigstens in manchen Fällen ein äusserer Reiz die Entscheidung darüber zu geben, ob das weisse Winterkleid oder das dunkle Sommerkleid auftreten soll, und zwar ist es aueh hier die Temperatur der Umgebung,

1) Siehe: Zusatz 6 . 
welche als Reiz wirkt. Ein complicirter Nerven-Mechanismus muss bestchen, der, von der Kälte gereizt, seinerseits wieder die Gefässnerven der Haut so becinflusst, dass sie gewisse Veränderungen in der Ernährung, dem Wachsthum und dem Gasgchalt der Haare hervorrufen. Einige wenige gutc und sichere Bcobachtungen beweisen dies, besonders der von Kapitän J. Ross vor mehr als fünfzig Jahren bcobachtete Fall eines Lemmings von der HudsonsBai, der zuerst längerc Zeit in der Wärme gehalten wurde und dabei sein dunkles Sommerkleid im Winter bcibehielt, dieses aber innerhalb einer Woche mit dem weissen Winterkleid vertauschte, als er dcr Kälte ausgesetzt wurde ${ }^{1}$ ).

Während aber ein zeitlicher Anpassungs-Dimorphismus bei Insecten für jetzt nur vermuthet werden darf, wenn auch mit grosser Wahrscheinlichkeit, kennen wir eine andere Art von Doppelgestaltigkeit dersclben sicher, bei welcher es sich cbenfalls um protektive Färbungen handelt, und bei welcher die Entscheidung darüber, welche Färbung ins Leben treten soll, von der Qualität des Lichtes gegeben wird, das von der Umgebung des Thiercs ausstrahlt. Die schönen Versuche von Poulton an verschiedenen Raupen und Puppen beweisen dies. Die Raupen von Amphidasis Betularia, einem Spanner, nehmen die Färbung der Zwcige an, auf welchen sie von Jugend auf sitzen, und man kann sie schwarz, braun, weiss oder hellgrün werden lassen,

1) Der Fall wird von Poulton in seinem Buch, The Colours of Animals", London 1890, genau mitgetheilt. "Dort ist anch die ganze, hier nur leicht berihrte Frage nach den Ursachen des Winter- und Sommerkleids der arktischen Säugethiere und Vögel eingehend besprochen. 
ganz unabhängig vom Futter, je nachdem man sie zwisehen derart gefärbten Zweigen (oder aueh Papier) aufzieht ${ }^{1}$ ). Ebenso werden die Puppen von Vanessa Urtieae dunkelsehwarzbraun, wenn sie siel auf dunkelm Grund verpuppen, nehmen dagegen eine liehte Färbung an, oder sogar einen starken Goldglanz, wenn sie sieh auf liehtem Grunde befestigt haben. Aueh in diesen Fällen kann nieht daran gedacht werden, dass etwa die Anlage zur Vielgestaltigkeit selbst direet dureh das Licht entstanden wäre; als Anpassung kann sie vielmehr nur dureh Selectionsprocesse herrorgerufen worden sein, aber eine jede der auf diesem Wege entstandenen doppelten Entwicklungsmöglichkeiten der Hautfürbung hat ihre besondere Reiz-Empfindlichkeit für gewisse Liehtarten erhalten und wird nur dureh diese in Aktivität versetzt.

Dies leitet dann zu jenen Fällen hin, in welehen ein und dasselbe Individuum die Farbe in kurzer Zeit, beinahe momentan, wechseln kann, wie solches von vielen Fischen, Amphibien, Reptilien und Cephalopoden bekannt ist. Auch hier wirkt der die Färbung bestimmende Liehtreiz nicht direet auf die die Farbe bedingenden Elemente der Haut selbst, sondern es ist ein complieirter Nervenapparat zwischen sie und den Theil eingesehaltet, weleher zunächst rom Licht erregt wird: die Nervenendigungen in der Haut oder im Ange. Werden im letzteren Falle die Lobi optici des Gehirns kïnstlieh zerstört, dann hört die Fïhigkeit des

1) E. B. Poulton, "Further experiments upon the colourrelation between certain lepidopterous larvae, pupae, cocons, and imagines and their surroundings". Trans. Ent. Soc. London 1892, pp. 326-360 und Plate XIV, Fig. 8-18, Plate XV, Fig. 4. 
Farbenwechsels auf; derselbe beruht somit auf einem ReflexMeehanismus, dessen Entstehung wiederum nicht auf irgend einer direkt wirkenden Ursaehe, sondern nur auf Seleetionsprocesse bezogen werden kann. In diesem und ähnliehen Fällen ist die Zweigestaltigkeit nicht Folge einer zweifaehen Keimesanlage, von der nur die eine oder die andere zur Entfaltung kommen kann, sondern beruht auf der versehiedenen Reizbarkeit der verschiebbaren histologisehen Elemente, welehe in kunstvoller Zusammenordnung die Haut bilden.

Viele Thatsachen weisen darauf hin, dass aueh die Differenzirung des Gesehleehts in einem gewissen Umfang von dem bisher festgehaltenen Gesiehtspunkt aus betrachtet werden kann. Im Ei der höheren Thiere ist die Anlage zu den Charakteren beid er Gesehleehter enthalten, und in vielen Fällen wenigstens seheint es irgend ein Reiz zu sein, der die Entseheidung darïber giebt, welehe Gruppe von ihnen zur Entfaltung gelangen soll, die männliehe oder die weibliehe. Leider können wir für jetzt nur in sehr wenigen Fällen diesen entscheidenden Reiz mit Sicherheit naehweisen, aber soviel möehte wenigstens feststehen, dass derselbe nieht überall der gleiehe ist. Die bekannten Versuehe Yung's mit Frosehlarven deuten darauf hin, dass bei ihnen das Geschleeht dureh die Intensität der Ernährung mit bestimmt wird, und ähnliehe Erfahrungen sind von mehreren Forsehern aueh an Raupen gemaeht worden, bei denen aueh die Männehen in grösster Anzahl bei schwaeher Ernährung auftraten. Versuche von Ma up a s dagegen lehren, dass bei Hydatina senta, einem Räderthier des süssen Wassers, die Entseheidung durch die Temperatur gegeben wird, und zwar interessanter Weise derart, dass uiber das Gesehleeht der von einer Mutter hervor- 
zubringenden Kinder entschieden wird, ehe dieselben auch nur im Keim angelegt sind ${ }^{1}$ ).

Für Bienen und Wespen haben seinerzeit Siebold und Leuckart gezeigt, dass befruchtete Eier sich zu Weibchen entwickeln, unbefruchtete zu \ännchen. Wenn auch das "Wie" dieser Einrichtung noch völlig dunkel ist, so leuchtet doch wenigstens ihre Nützlichkeit ein, indem die Königin des Stockes durch sie in den stand gesetzt wird, nach Willkür und Bedürfniss männliche oder weibliche Nachkommen hervorzubringen. Soweit also verstehen wir, warum das Geschlecht hier ron einem äusseren Reiz abhängig gemacht wurde. Hier wird wohl auch Niemand auf den Einfall kommen, den auslösenden Reiz fiir die bewirkende Ursache der Weiblichkeit oder Männlichkeit des Embryos zu halten, so wenig als man die Wärme, welche zur Entwicklung eincs Taubeneies nothwendig ist für die Ursache ansicht, dass eine Taube und nicht eine Ente sich aus ihm entwickelt ${ }^{2}$.

Aber in anderen Fällen liegt das weniger auf der Hand, und der ausschlaggebende Reiz wird leicht für dic causa efficiens der Bildung genommen.

Es sei mir gestattet, auf einen solchen Fall hier etwas genauer einzugehen, der mir von ganz besonderem Interesse zu sein scheint, und der trotz seiner allgemeinen Bekanntheit doch noch keineswegs ganz klargelcgt ist. - Ich spreche von den Neutra oder Arbeiterinnen der staatenbildenden Insekten, der Bienen, Ameisen und Termiten. Bekanntlich nehmen diese Arbeiter nicht etwa

1) Siehe: Zusatz 7.

2) Siehe: Zusatz 8 . 
aus besonderen Eiern ihren Ursprung, sondern es ist für Bienen und Termiten nachgewiesen und auch für Ameisen sehr wahrscheinlich, dass überhaupt nur eine Art ron Eiern existirt, aus welchen neben Männchen sowohl Königinnen als Arbeiterinnen hervorgehen können. Erstere entstehen, wenn weibliche Larven sehr reichlich und nahrhaft gefüttert werden, letztere, wenn sie weniger und minder nahrhaftes Futter erhalten. Die Unterschiede zwischen den beiden Kasten sind mannigfache, aber ich möchte fürs Erste nur eines dieser Merkmale ins Auge fassen: die Sterilität der Arbeiterinnen, ihre relative, unter Umständen auch ihre absohute Unfruchtbarkeit.

Fragen wir zunächst, wie ist diese Sterilität entstanden, so möchten wohl Viele sie für die directe Folge der minderwerthigen Ernährung der Larve halten. Diese Antwort ist auch schon öfters ${ }^{1}$ ) und erst in jüngster Zeit wieder von Herbert Spencer gegeben worden; ich kann sie aber in dem Sinne, in dem sie gemeint ist, nicht für richtig halten. Wohl ist es richtig, dass die Bienen es in der Hand haben, aus einer Larve eine Königin oder eine Arbeiterin werden zu lassen, je nachdem sie dieselbe füttern, wohl ist es auch richtig, dass alle Thiere ganz im Allgemeinen sich bei schlechter und knapper Nahrung nur schwach oder gar nicht fortpflanzen, dennoch aber ist die minderwerthige Nahrung nicht die causa efficiens der Sterilität der Bienen, sondern sie ist nur der auslösende Reiz, der

1) So z. B. von William Marshall in seinem hiibschen Schriftchen "Leben und Treiben der Ameisen", Leipzig 1889. 
nicht nur die Bildung rudimentärer Eierstöcke hervoruft, sondern zugleich alle iibrigen unterscheidenden Charaktere der Arbeiterinnen. Wer die minderwerthige Nahrung für die wirkliche Ursache laält, der begeht meines Erachtens einen doppelten Irrthum. indem er einmal den auslösenden Reiz mit der wirklichen Ursache verwechselt und zweitens das Rudimentärwerden eines Organs mit dessen bloss unrollständiger Entfaltung. Er iibersieht, dass die Eierstöcke der Arbciterinnen wirklich rudimentiire Organe sind, Organe, an denen ein grosser Theil der ihnen zukommenden wesentlichen Stiicke geschwunden, und nur ein kleinerer noch erhalten ist. Die Bienen-Königin hat 180-200 Eiröhren in ihrem Eierstock, in deren jeder sic zahlreiche Eier zur Reife bringen kann; dementsprechend vermag sie im Laufe ihres Lebens eine ungeheure Zahl ron Eiern zu legen, woll über hunderttausend. Der Eierstock der Arbciterin enthält nur zwei bis sechs Eiröhren, und durch noch so reichliche Nahrung können in ihr kcine neuen Eiröhren mehr gebildet werden. Wohl legen auch die Arbeiterinnen gelegentlich Eier, und zwar wohl dann, wenn sie als Imagines ausnahmsweise noch reichliche Nahrung erhalten, aber auch in diesem Falle bleibt ilıre Fruchtbarkeit eine geringe, weil eben in den wenigen vorhandenen Eiröhren nur wenige Eier glcichzeitig zu reifen Platz haben. Für gewöhnlich geschieht auch dies nicht, weil die Arbeiter-Bienen nicht mehr Nahrung zu sich nehmen, als eben grade für die Erhaltung ihres Körpers ausreicht, nicht aber soviel, wie nöthig wäre, um auch noch die winzigen Eikeime in ihren Eiröhren zu grossen, reifen Eiern heranwachsen zu lassen.

Man kann nun durch den Versuch erweisen, 
dass sehlechte Ernährung durchaus keine Verkümmerung' der Eierstöcke bei den Insecten naeh sich zieht.

Die Fliegen (Diptera) ähnchn den Bienen biologiseh in vieler Beziehung; sie entwickeh sieh aus fusslosen Maden, welche sich mitten in der für sie passenden Nahrung befinden und fast unausgesetzt Nahrung aufnehmen; sie wachsen rasch heran, geben nach kurzer Puppenruhe das vollendete Insect und pflanzen sich dann bald und reichlich fort. Ich habe nun zahlreiche, von einem Weibchen der Schmeissflicge (Musea vomitoria) gelegte Eier in zwei Parthieen getrennt aufgezogen, und zwar die erste Abtheilung bei ununterbroehen reiehlieher Ernährung, die andere bei mögliehst kärglicher Fütterung. Diese wurdc einfach dadurch bewerkstelligt, dass die Larven zeitwcise aus dem Fleisch, in welches sie sich eingebohrt hatten, herausgenommen und dann eine Reihe von Stunden hindureh ohne Nahrung belassen wurden ${ }^{1}$ ). Diese Larven wuchsen langsam und blieben alle mehr oder weniger auffallend klein. Zeitlich wurde aber ihre Entwicklung nicht aufgehalten; sie verpuppten sich viehmehr gleichzeitig mit den normal gefütterten Larven, nur wenige um einen Tag später. Die Larvenperiode dauerte bei beiden neun bis zehn Tage, die Puppenperiode 28-29 Tage. Fast gleichzeitig schlüpften alle Zuchtthicre - mehrere Hunderte aus der Puppe und wurden von da ab in grösseren luftigen Zwingern, der Somne ausgesetzt, gehalten und reichlieh mit Nahrung versehen.

Wenn nun die Fortpflanzungsorgane durch die schleehte Ernährung rudimentär geblieben wären, so hätte sich dies

1) Siehe: Zusatz 9 und 10. 
dadurch zeigen muissen, dass die Hungerfliegen sich nicht oder schwach fortgepflanzt hätten. Allein dem war nicht so. Obgleich die Hungerfliegen alle kleiner als gewöhnliche Fliegen, viele sogar auffallend klein waren, also zweifellos weniger Stoff aufgenommen hatten, als die normal gefuitterten Larven, so legten sie doeh an demselben Tag, dem 6. Juni, zum ersten Mal eine Masse von Eiern ab, an welchem auch die letzteren mit der Eiablage begannen, und dabei hatte es nieht sein Bewenden, sondern die Eiablage wiederholte sich später noch oft. Um aber sicher zu sein, dass aueh die kleinsten, also die am stärksten von der sehlechten Ernïhrung betroffenen Thiere sich fortpflanzten, isolirte ich fünf der kleinsten Fliegen. Sehon nach sieben Tagen hatten sie zwei grosse Packete Eier abgelegt, und dies wiederholte sieh in den näehsten vierzehn Tagen noeh vier Mal.

Es konnte also kein Zweifel dariuber bestehen, dass trotz der geringen Stoffzufuhr während des Larvenlebens die Fortpflanzungsorgane, wenigstens die keimbereitenden Eierstöeke, völlig normal angelegt worden waren, so dass sie bei guter Ernährung während des Imago-Lebens eine vollkommen normale Fortpflanzung ergeben konnten.

Dass aber auch die Copulationsorgane und die männliehen Organe normal angelegt waren, stellte ich dadureh sieher, dass ieh das Vorkommen parthenogenetiseher Entwieklung bei dieser Art aussehloss. Ieh isolirte eine Reihe einzelner Weibchen unmittelbar nach ihrem Aussehlüpfen aus der Puppe in kleineren Zwingern und fütterte sie reiehlieh. Aueh sie legten naeh einiger Zeit Eier ab, allein kein einziges derselben entwiekelte sieh zur Larve. Daraus folgt, dass die Eier von Musea vomitoria der Fähigkeit ent- 
bchren, sich auf parthenogenetischem Wege zu entwickchn, und dass somit alle jene Eierder Hungerfliegen, von denen vorhin die Redc war, befruchtet waren. Diescs aber ist nur möglich, wemn auch der gesammte männliche Fortpflanzungs-Apparat bei ihnen normal gewesen war. Der Versuch beweist dies noch sicherer, als es durch anatomische Untersuchung geschehen könnte, und damit ist der Beweis geliefert, dass kein Theil der Fortpflanzungs-Organe durch die beschränktc Stoffzufuhr während der Larvenperiode in irgend eincm Grade verkümmert war.

Vergleicht man das Ergebniss dieser Versuche mit den bekannten Thatsachen bei den Bienen, so wird der Unterschied in dem Verhalten beider Organismen klar. Bei der Biene entsteht durch minderwerthige Ernährung eine starke Verkümmerıng der Ovarien und verschiedener Nebenorgane der Fortpflanzung, bei den Fliegen bildet sich der gesammtc Fortpflanzungs-Apparat gerade so vollständig aus bei schwacher Ernährung der Larven als bei vollwerthiger. Nicht einmal eine Verzögerung der Eireife tritt ein, wic daraus hervorgeht, dass die erste Eiablage der Zeit nach genau zusammenfiel mit derjenigen von Flicgen aus normal gefütterten Larven.

Man wird mir darauf antworten, Fliege und Biene seien eben zwei verschiedenartige Organismen, welche dcshalb auch verschieden auf äussere Einfliussc reagirten. Dies ist sehr richtig, ist aber gerade das Zugeständniss, welches ich verlange; meine Versuche mit den Fliegen sollten nichts weiter bewcisen, als diesen Satz, dass nicht jedes Insect, auch wenn es sonst mancherlei Aehnlichkciten mit der Biene hat, auf minderwerthige Ernährung so reagirt, wie die Bienc, dass somit diese Reactionsweise eine 
Eigenthümliehkeit der Biene ist, eine Neuerwerbung, welehe die Urinsecten noch nicht hatten. Dennoeh kann ich der Auffassung eines so ausgezeichneten Ameisenkenners, wie C. Eméry es ist, nicht völlig beistimmen ${ }^{1}$ ), wenı er kürzlieh diese Verkiimmerung der Ovarien bei den Arbeiterinnen nur als die Folge einer erhöhten Empfindlichkeit "des Keimplasma's" für minderwerthige Ernährung linstellte, ja sogar die ganze Erscheinung der Bildung von Neutra bei den Insecten für die Folge ciner solchen veränderten Reactionsweise des Keimplasma's erklärte. In ganz allgemeinem Sinn kann man ja sagen, dass der Larvenorganismus cine eigentlümliche Reizempfindliehkeit in Bezug auf Ernährungsunterschiede erlangt habe, aber wenn damit gemeint ist, dass die Anlage des Ovariums leichter auf schwache Ernährung im Wachsthum und der Entwicklung zurickbleibe, als die Ovarien anderer Insecten, dann ist diese Amiahme nicht ausreichend und auch iiberhaupt nicht richtig.

Sie reicht nicht aus zur Erklärung der Thatsaehen, weil ebcn das Orarium der Arbeiterin nicht bloss unausgebildet, sondern wirklieh rudimentär ist. Es fehlt ihm die grösste Zahl der typisehen Stücke, welche ihm von Rechtswegen zukämen. Wenn auch anzunehmen ist, dass die Zahl der Eiröhren sich im Ovarium der Königin noch vermehrt hat, seitdem die Kaste der Arbeiterinnen entstand, so kann doeh darüber kein Zweifel sein, dass sie gleichzeitig bei den Arbeiterinnen bedeutend abgenommen hat.

1) C. Emery "Die Entstehung und Ausbildung des Arbeiterstandes bei den Ameisen". Biolog. Centralblatt vom 15. Jan. 1894. 
Das gcht schon aus den Befunden hervor, wclche A d le $\mathrm{rz}^{\mathbf{1}}$ ) bei Ameisen erhalten hat, und nach welchen dic Verminderung der Eiröhren bei verschiedenen Arten verschieden gross ist und von zwölf bis auf eine, ja bei Tetramorium Caespitum bis auf das gänzliche Fehlen derselben herabgeht. Der rudimentäre Zustand der Fortpflanzungsorgane tritt aber noch schärfer hervor, wenn man erwägt, dass auch Bursa Copulatrix und Receptaculum seminis bei Bienenund Ameisen-Arbeiterinnen verkümmert sind. Alle Erfahrung spricht aber dafür, dass typische Theile niemals durch noch so schlechte Ernährung ausfallen können, eine Eiröhre so wenig, als ein Bein oder ein Fliigel. Wie oft hat man schon Raupen en masse unter Hungerkost aufgezogen, absichtlich oder aus Unachtsamkeit, aber noch niemals ist daraus ein Schmetterling ohne Flïgel, oder mit nur vier Beinen, statt seiner sechs, hervorgegangen. Alles, was man dadurch erreichte, waren sehr kleinc, aber vollständig ausgebildete Thiere. Dasselbe war bei meinen Hungerfliegen zu beobachten. Der A usfall eines typischen Organs ist kein ontogenetischer Process, sondern ein phylogenetischer, er beruht nie und in kcinem Falle auf den blossen Ernährungscinflïssen, welche die Entwickelung des cinzelnen Individums treffen, sondern stets auf Acnderungen der Keimesanlagen, wic sie allem Anschein nach nur in langen Generationsfolgen zu Stande kommen können²).

Deshalb ist die Annahme, dass blosse Erhöhung der

1) Adlerz, G., "Myrmecologiska studier" in Bih. Srenska Vet. Akad. Haudl., 11. Bd., Nr. 18. 1887.

2) Siehe: Zusatz 13. 


\section{$-31-$}

Empfindliehkeit für schwaehe Emährung die Ursaehe sei, dass bei den Arbeiterinnen ein Ovarium mit wenigen oder gar keinen Eiröhren gebildet wird, nicht ausreichend. Wir müssen vielmehr annehmen, dass im Keimplasma des Eies die Anlagen zu zwei ganz verschiedenen Fortpflanzungssystemen enthaltensind, zu dem der Königin und dem der Arbeiterin.

Aber selbst in Bezug auf die Reifung der einmal vorhandenen Eikeime dürfen wir sehwerlich den soeialen Insecten eine erhöhte Empfindlichkeit für minderwerthige Nahrung zuschreiben. Wir finden bei vielen Thieren diese Empfindlichkeit in hohem Grade ausgebildet. Ieh erinnere z. B. an meine alten Beobachtungen iiber die Auflösung halbreifer Eier im Ovarium der Daphniden, sobald die Thiere nieht hinreichend Nahrung erhalten ${ }^{1}$ ). Wie sehr die Reifung der Eier der Inseeten ron der Ernährung abhängt, lehrten auch meine Fliegen, welche bei minderwerthiger Nahrung im Imago-Zustand ïberlo a upt keine Eier ablegten und die Orarien in demselben unreifen Zustand beibehielten, wie sie sie stets aueh bei reichlichster Larvenernährung - aus der Puppe mitbringen.

So bieten also die Thatsaehen weder einen Anhalt dafürr, dass die Verkümmerung des Arbeiter-Ovariums eine directe Folge minderwerthiger Ernährung sei, noeh dafür, dass iiberhaupt eine erhöhte Empfindliehkeit des Ovariums für Ernährungseinflïsse hier vorliege. Wohl aber lehren sie uns, dass minderwerthige Fitterung die Rolle des auslösenden Reizes für die im Keimplasma

1) Siehe: Zusatz 11. 
anzunehmende Anlage der Arbeitcrin spielt, nicht nur der Anlage ihres Orariums, sondern zugleich aller Charaktere, durch welche sich die Arbeiterin von der Königin unterscherdet.

Es klingt nun zunächst vielleicht sonderbar, dass in ein und demselben Ei eine doppelte Anlage zahlreicher Körpertheile enthalten sein soll, allein das Ueberraschende daran verliert sich, wenn man erwägt, dass ja in jerlem Ei der meistcn Thiere zweifellos viele Körpertheile in doppelter Anlage enthalten sein müssen, in einer weiblichen und einer männlichen. In manchen Fällen sind diese Anlagen sogar auf zwei vcrschiedene Arten von Eiern vertheilt, so bei Räderthieren und bei der Reblaus, und hier kann es also nicht bezweifelt werden, dass jedes Geschlecht seine besondere Keimesanlage hat. Ist das aber hier so, dann sehe ich nicht ein, was uns zu einem Zweifel daran berechtigte, dass in den Eiern der geschlechtlich dimorphen Thiere allg emein doppelte Anlagen vorhanden sind, wenn auch noch nicht auf zwei verschiedene Eier vertheilt, sondern in demselben Keimplasma beisammen liegend, eine Vorstufe jener denkbar stärksten Geschlechtertrennung. Von hier aus aber gelangt man dann ohne Sprung zu den Verhältnissen bei den socialen Insecten, bei welchen mindestens dreierlei verschiedene Anlagen des Körpers im Keim enthalten sein müssen, indem die Weibchenanlage in zweifacher Gestalt vorhanden ist.

Fragen wir aber nun, wie die Rückbildung der Ovariums-Anlage entstanden sein könne, so ist es klar, dass sie nicht etwa Folge von Nichtgebrauch sein kann, da die Unfruchtbarkeit in demselben Grade aufhört, sich zu vererben, in dem sie sich ausbildet. Mir scheint des- 
halb ein gcradezu zwingender Beweis in dem relativen Schwinden der Eiröhren bei den Arbeiterimnen der Bienen und Ameisen zu liegen dafür, dass cs Täuschung ist, wenn man die Terkümmerung irgend cines Organs als directe Folge des Nichtgebrauchs auffasst, da hier gerade diejenigen Organe schrittweise ver. kümmerten, an welchen die Vercrbung hängt, somit nichts von ihrer Verkümmerung vererbt werden konnte. Dennoch ging die Rückbildung des Ovariums ihren langsamen phyletischen Gang Schritt für Schritt weiter, brachte eine Eiröhre nach der andern zum schwund, gerade wie irgend ein nicht mehr gebrauchtes Organ, z. B. die iiberfliussigen Zehen der Urpferde, die auch scheinbar durch directe Wirkung des Nichtgebrauchs verkümmern und ihre Verkïmmerung auf die Nachkommen vererben. Und doch gibt es hier keine Nachkommen! Das sind Thatsachen, die nicht stark genug geltend gemacht werdeu können, und die sich jene Geologen doch einmal näher ïberlegen sollten, welche so sicher dem Schein trauen und eine Vererbung erworbener Eigenschaften als einen bewiesenen Torgang annehnen, weil es in zahlreichen, ja in den allermeisten Fällen ganz so a ussieht, als wäre der Schwund directe Folge des Nichtgebrauchs. Der Schein trügt bekanntlich öfters und hat bisher in der Wissenschaft nicht olne Weiteres schon als Beweis gegolten. Oder wollen wir wieder zu der Ansicht zuriickkehren, dass die Sonne um die Erde lïuft? lch wïsste nicht, dass gegen diesen falschen Schein beswere Beweise anzuführen wären, als sic in den eben vorgebrachten Thatsachen gegen den Schein einer Vererbung erworbener Eigenschaften enthalten sind.

Wir kömmen also fur die Verkümmerung der FortWe ismann, Reize uml Ursachen. 
pflanzungsorgane hier nur Selectionsprocesse verantwortlich machen, und dies begegnet auch keinem Hinderniss, insofern diese Verkiimmerung hier eine zweckmässige, vortheilhafte Einrichtung ist, durch die die Arbeiterinnen erst befähigt wurden, ihre ganze Kraft der Arbeit zuzuwenden. Der Vortheil der Arbeiterkaste ist schon so oft dargelegt worden, dass ich wohl darauf näher einzugehen unterlassen darf.

Wenn aber nun weiter gefragt wird, wie es iiberhaupt denkbar sei, dass zwei- oder gar dreierlei Anlagen der entsprechenden Organe in einem Keim enthalten sein und auf welchem Wege sich dieselben entwickelt haben können, so scheint mir dies ron der Grundlage der von mir früher entwickelten Vererbungstheorie aus nicht so schwer begreiflich zu sein. Ich stelle mir das Keimplasma nicht als einen einzigen Keim für den Aufbau eines Individuums vor, sondern ich denke mir, dass es eine grössere Zahl secundärer Einheiten enthält, deren jede alle die Anlagen in sich birgt, welche zum Aufbau eines Individuums gehören; es sind dies meine Ide. Nehmen wir diese Hypothese einmal an, so unterliegt es keiner Schwierigkeit, sich rorzustellen, dass das Keimplasma der heutigen Bienen sich aus verschiedenen Iden zusammensetzt, von welchen ein Theil die Anlagen zur Arbeiterin, ein anderer die zur Königin, ein dritter die zum Männchen enthält, und es steht nichts im Wege, sich die Arbeiter-Ide der Ameisen wieder von zweierlei Art zu denken, als Arbeiter-Ide im engeren Sinne und als Soldaten-Ide. Die männlichen Ide werden actir beim Ausbleiben der Befruchtung, die weiblichen bei ihrem Eintritt, und die Art der Ernährung bildet den auslösenden Reiz für die Arbeiter-Ide oder die 
Königinnen-Idc. Langsame Selectionsprocesse haben die weiblichen Ide allmählich nach zwei Richtungen umgestaltet und schliesslich zur vollen Zweigestalt der weiblichen Thiere gefühırt. Dass dieser Process nicht plötzlich, sondern schrittweise vorgerückt ist, können wir heute noch sehen, denn lieute noch sind uns eine ganze Anzahl von Stufen dieser Umwandlungen in den Arbeiterinnen der verschiedenen Ameisenarten erhalten. Auch sporadische Uebergänge zwischen Arbeiterinuen und Weibchen kommen vor, und in ziemlich verschiedenen Combinationen der Merkmale, ähnlich den Zwitterbildungen jener sonderbaren und oft ganz regellosen Mischung der Geschlechtsunterschiede, wie sie abnormer Weise zuweilen vorkommen und gerade bei den Bienen in so wunderbarer Mannigfaltigkeit beobachtet wurden. Wenn irgend etwas dafür spricht, dass in der That der Keim aus Iden, und diese wieder aus Anlagen der einzelnen selbstständig variabeln Theile des Körpers, aus "Determinanten" zusammengesetzt sind, so sind es gerade diese Thatsachen, wie sie die stufenweisen Umwandlungen der Weibchen zu Arbeiterinnen bei den staatenbildenden Insecten uns aufweisen. Zuerst - so werden wir annehmen müssen - wandelten sich nur kleinere Gruppen von Determinanten um, etwa diejenigen der Fortpflanzungsorgane und der Flügel bei den Ameisen, zugleich auch viele Determinanten des Gehirns; es kamen neue Determinanten hinzu, fielen alte aus, und indem so nach und nach immer zahlreichere und ausgedehntere Gruppen von Determinanten immer stärker abänderten, wurde schliesslich das Id im Ganzen ein neues, ein Arbeiter-Id. In ähnlicher Weise wandelten sich andere Weibchen-Ide zu Königinnen-Iden um, und bei den Ameisen mit Soldaten 
differenzirte sich ein Theil der Arbeiterin-Ide zu SoldatenIden ${ }^{1}$ ).

Durch die aus ganz andern Thatsachen abgeleitete Annahme einer Zusammensetzung des Keimplasmas aus Iden werden - wie ich glauben muss - die sonst so dunkeln Erscheinungen des Polymorphismus klar und verständlich, sowohl als fertige Erscheinungen, wie auch in ihrer phyletischen Entwicklung. Und dies Alles, ohne dass irgend welche nene und speciell auf diesen Fall berechnete Annahmen gemacht werden müssten. Es verläuft vielmehr Alles genan so, wie es im Allgemeinen bei jedem Umwandlungsprocess anzunehmen ist. In allen Fällen - so schloss ich aus den Erscheinungen der Vererbung - werden beim Beginn einer Umwandlung die Determinanten derjenigen Theile umgewandelt, welche sich neuen Forderungen der Lebensbedingungen anzupassen haben. Aber auch diese primären Abänderungen beruhen nicht von vornherein auf einer Umwandlung der homologen Determinanten aller Ide, sondern nur eines Theils derselben, einer kleinen Majorität, wie sie gerade ausreicht, um den abgeänderten Charakter in's Leben zu rufen. Allmählich erst und mit Hülfe von Amphimixis und Reductionstheilung mehrt sich dann die Zahl der so abgeänderten Ide, und gleichzeitig ändern sich nun auch die Determinanten anderer cooperirender Körpertheile, bis schliesslich beinahe oder wirklich alle in irgend einem, zum Theil sehr geringen, zum Theil grösseren Betrag abgeändert, und so die betreffenden Ide etwas Neues geworden sind. Es ist genau derselbe Vorgang, wie er auch bei der Bildung der Arbciterinnen

1) Siehe: Zusatz 12 und 16. 
von Ameisen und Bienen angenommen wurde, mit dem einzigen Unterschied, dass dort niemals alle oder auch nur die meisten Ide zu Arbeiterin-Iden werden durften, sondern nur ein bestimmter Procentsatz derselben, da ja die fruchtbaren Weibehen nothwendig für die Art blieben, also ebenfalls durch cine Anzahl von Iden im Keimplasma vertreten bleiben mussten. Aber auch bei der gewöhnlichen Unwandlung einer Art werden - wem mcine Vorstellung richtig ist - immer cinige Ide unverändert oder nu wenig verändert noch lange Zeit mitgefülı't, wie wir ans den Rückschlagerscheinungen schliessen können. Wähırend aber hier dicse nicht abgeänderten Ide keinc Bedeutung für die Art mehr haben und deshalb dureh Reductionstheilung immer mehr verschwinden können, bis zuletzt höchstens noch einzelne alte Determinanten-Gruppen in manchen Iden enthalten sind, kommt es bei den socialen Insecten darauf an, dass sich ein festes Verhältniss zwischen alten und neuen Iden herstelle, und auch diesen Vorgang werden wir nur auf Rechnung ron Selectionsprocessen setzen können. Wenn im Keimplasma der Biene nur einc Anlage vorhanden wäre, welche dic Fähigkeit besässe, sich auf die Einwirkung reichlicher Ernählrung zur Königin, auf die minderwerthiger Ermährung zur Arbeiterin zu entwickeln, wie wollte man es erklären, dass durch die letztere Einwirkung nicht bloss Verkümmerung einzehner Theile, sondern auch Anders- und Stärker-Entwicklung andercr Theile eintritt? Mir scheint, dass wir keine Wahl haben, dass wir schon allein durch die socialen Insecten gezwungen sein würden, die Amnahme von Iden zu machen, denn nur so wird es verständlich, wie durch den Reiz minderwerthiger Ernährung ganz cntgegengesetzte Charaktere hervorgcrufen 
werden kömmen, einerseits Rückbildungen an den Ovarien, dem Receptaculum, den Flügeln, oft auch bedeutende Reduction der gesammten Körpergrösse, andererseits Steigerungen und Höher-Differenzirungen einzelner Theile, wie des Gehirns bei den Amcisen-Arbeiterinnen, der Kiefer bei den Soldaten und in Verbindung damit vicler Instincte. Nichts von allen diesen Veränderungen beruht in seinem eigentlichen Grund auf directer Wirkung der minderwerthigen Nahrung, nicht eimmal die häufig so auffallende Kleinheit der Ameisen-Arbeiterinnen! Versuchen Sie es eimmal, aus irgend einem Insect durch Hungern während der Entwicklung Zwergformen zu machen, Sie werden es höchstens bis auf die halbe Grösse bringen, so wie es zuweilen bei den erwähnten Schmetterlingen und auch in meinen Fliegen-Versuchen eintrat. Allein die Arbeiterinnen mancher tropischer Ameisen (Atta fervens) sind zehn Mal kleiner als ihre fruchtbaren Weibchen, und wenn auch ein Theil dieses Unterschiedes auf phyletische Vcrgrösserung der Weibchen zu setzen ist, so kommt doch ein anderer beträchtlicher Theil davon zweifellos auf Rechnung: einer Verkleinerung der Arbeiterinnen ${ }^{1}$ ). Eméry hat deshalb insoweit recht, wenn er meint, dass die Entstehung solcher Zwergarbeiterinnen auf einer besonderen Eigen-

1) Dies geht daraus hervor, dass die Männchen ebenfalls sehr viel grösser als die Arbeiterinnen sind; die Weibchen messeu hier $22 \mathrm{~mm}$, die Männchen 17, die Soldaten 11 und die Arbeiter von 1,6 bis $9,6 \mathrm{~mm}$. Uebrigens ist der Unterschied in der Körpergrösse zwischen Geschlechtsthieren und Arbeitern anch bei einigen unserer einheimischen Ameisen, z. B. bei Lasius brunneus schon so bedeutend, dass man die beiderlei Formen zuerst für ganz verschiedene Arten halten möchte. 
schaft des Keimplasmas beruhen müsse, „nämlich darauf, dass die mangelhaft ernährten Larven nicht verhungerten, sondern klein blieben und sich verpuppten". Nur dass diese "besondere Eigenschaft des Keimplasmas" nicht bloss in einer veränderten Rizbarkcit desselben besteht, sondern in einer Umgestaltung eines Theiles desselben, welches eben in den Arbeiter-Iden derart abändertc, wie es zur Herstellung eines Körpers von kleinen Dimensionen erforderlich war. Denn man wird doch nicht ernstlich glauben wollen, dass dicse Larven wirklich "mangelhaft" ernährt und thatsächlich „durch Hunger" klein gehalten wiirden? Sie werden vielmehr genau so viel Nahrung erhalten, als sie zur Entwicklung der Arbeiteranlage branchen, und als ihr Instinct verlangt, sobald sie durch Verabreichung der minderwerthigen Ernährung einmal Arbeiterlarven geworden sind. Die Instinctanlagen der Arbeiter-Ide sind eben auch abgeändert worden, gerade so wie diejenigen der Königinnen-Ide. Hand in Hand mit den sichtbaren Veränderungen des Körpers sind unsichtbare gegangen, die wir eben nur aus der Veränderung der Instincte erschliessen können. Wir wissen aber, dass die "Kunst", durch eine bestimmte Nethode der Fütterung aus der Larve cine Arbeiterin oder eine Königin zu erziehen, ein Instinct ist, der sich erst mit der Entwicklung der Arbeiterform ausgebildet haben kann, und ebenso wird sich der Instinct eines geringeren Nahrungsbediurfnisses bei der Arbeiterinlarve glcichzeitig damit entwickelt haben. Denn die Arbeiterinlarve ist ein besonderes Individuum mit ihren eigenen und eigenthimlichen Anlagen und Instincten, so gut als die ausgebildete Arbeiterin. Drei Tage lang nur erhalten alle Larven der Biene dasselbe Futter, und 
so lange sind sie indifferent und können noch Arbeiterin oder Königin werden, damn aber tritt verschiedene Fütterung und damit die Entscheidung ein, welche Ide in dieser Ontogenese die Führung übornehmen sollen. Daran würde nichts geändert, wenn auch ältere Arbeiterlarven durch Verabreichung königlichen Futters noch zu Königinnen gemacht werden könnten, denn die Ide mit den Königinnenanlagen gehen jat nicht zu Grunde, sondern werden mit den übrigen Iden ron Zelle zu Zelle weitergegeben durch die ganze Ontogenese hindurch, und wenn sie eimmal so eingerichtet sind, dass sic bei einer gewissen Qualität und Quantität der Nahrung activ werden, so mögen sie dazu auch später noch im Stande sein, solange die Theile des vollendeten Insectes noch nicht angelegt sind. Bei den Bienen ist es nicht so; die Bienenzüchter wenigstens geben an, dass zur Aufzucht einer "künstlichen" Königin nur ganz junge Larven im Alter von 1-4 Tagen von den Arbeiterinnen gewählt werden. Bei den Termiten aber können nach Grassi auch noch ältere Larren nach der Willkür der sie fütternden Arbeiterinnen zu fruchtbaren Wcibchen ausgebildet werden, und zwar auch durch intensivere Ernährung mittelst eines nährenden Secrets ihrer Speicheldriisen ${ }^{1}$ ).

Gewiss ist diese ganz übereinstimmende Anpassung des Larvenorganismus an den bestimmenden Reiz einer specifischen Ernährungsweise, wie sie zwei so fernstehenden Insectengruppen zukommt, den Bienen und Termiten, sehr bemerkenswerth, denn es kann natürlich kein Zweifel darüber sein, dass sie in jeder Gruppe selbstständig ent-

1) Siehe: Zusatz 14. 
standen ist. Aber iiberrasehend erscheint es mir nicht, dass Naturziiehtung bei beiden die Auslösung der Kastenanlagen gerade an Nahrungsreize geknuipft hat. Diese Convergenz scheint mir vielmehr so verständlich, als dic selbstständige Entstehung von Augen ähnlicher Bildung in ganz verschiedenen Thiergruppen. Welch'anderer Reiz hät te auch diese Auslösung übernehmen und zugleieh in die Maeht und Willkiir der Thiere gelegt werden kïnnen?

Man könntc antworten: Temperaturen verschiedener Höhe, allein dies wäre schwerlich" durchfïhrbar gewesen.

Allerdings tragen die Ameisen ihre Puppen zeitweise in die Sonne, und so gut beim adaptiven Saisondimorphismus die verschiedenen Traehten der Art für bestimmte Temperaturen reizempfindlich gemaeht werden kounten, wäre es Naturziichtung an und für sich wohl auch möglich gewesen, die Auslösung des Arbcitercharakteren-Complexes an Temperaturreize zu kniipfen, allein wie hätten die Thiere bestimmte Temperaturen für ihre Larren herstellen sollen, da sie doch nieht über den Somnenschein verfügen und noch weniger iber einen Eiskeller?

Dass aber Ernährungsunterschiede zum bestimmenden Reiz wurden, begreift sieh gut, da das Fuittern der Larven schon lange Zeit vor der Einrichtung der Insectenstaaten bei den solitären oder in kleinen Gesellschaften lebenden Hymenopteren iblieh war. Hier konnte also Naturziuchtung eingreifen und eine bestimmte Fütterungsweise begünstigen, gleichzeitig aber auch solehe Töchterlarven, bei welchen sieh ein 'Theil der Ide nach der Richtung der Arbeiterin hin verändert hatte. Im Genaucren können wir freilich diesen Umwandlungsvorgang noch nicht verfolgen. Es wäre 
auch verfrüht, heute schon fragen zu wollen, wie es minderwerthige Ernährung anfange, gerade die Arbeiter-Ide zur Aetivität zu bringen. Das lässt sieh zur Stunde noeh so wenig begreifen, als wir verstehen, auf welcher Eigenthümliehkeit des Wurzelgewebes einer Pflanze es beruht, dass sie auf den Reiz der Sehwerkraft abwärts und nicht, wic der Stamm, aufwärts wäehst. Wir müssen uns für jetzt damit beruhigen, anzunehmen, dass durch Selectionsproecsse cine solehe Reactionsweise eingeriehtet werden konnte, da wir für das Zwcekmässige einen anderen Ursprung nieht kennen.

So geht offenbar Alles bei dieser ganzen Umwandlungsgesehichte auf Seleetion zuriiek. Man hat mir öfters vorgeworfen, ieh übertriebe die Wirkungssphärc der Naturzüchtung, indem ich einseitig die directe Wirkung äusserer Einflïsse in den Hintergrund stellte. Ich glaube aber, heute an einem Beispiel gezeigt zu haben, dass man umgekehrt leieht geneigt ist, äussere Einfliisse für Umwandlungen verantwortlieh zu maehen, an denen sie keinen Antheil haben können. In diesem Falle muss Alles, was an den Arbciterinnen verändert worden ist, auf Selection beruhen, die Verkïmmerung der Eierstöcke, die Abänderung des eigenen Nahrungsbedürfnisses im Larven- und Imagoleben, die Entstehung der Kunst, selbst Arbeiterinnen oder Königinnen zu erziehen, und alle körperliehen Vervollkommnungen oder Rüekbildungen, welehe sie durchgemaeht haben ${ }^{1}$ ).

Gewiss! Es sind wunderbar vielseitige Wirkungen, welehe Naturzïehtung bei der Bildıng der Inseetenstaaten

1) Siehe: Zusatz 15. 
zu Stande gebracht hat, und man ist wohl berechtigt, zu fragen, ob denn auch so intensive Züchtungsprocesse gerade bei staatenbildenden Thieren möglich sind. Vor mehreren Jahren hat $\mathrm{Wolff}^{1}$ ) die Ansicht geäussert, von Selectionsprocessen könnte hier ïberhaupt nicht dic Rede sein, weil hier das um's Dasein kämpfende und das variirende Individuum "zwei verschiedene" Individualitäten seien -nämlich der Stock und die einzelnen Personen, die ihn zusammensetzen. In der That wiurden Variationen einzelner Individuen unter den ricken Tausenden eines Stockes ganz wirkungslos auf den Kampt um's Dasein bleiben, den der Stock als Ganzes zu kïmpfen hat. IV olff hat aber iibersehen, dass der Stock als Ganzes auch eine Variationseinheit bildet, wemn auch keine absolute, insofern eben alle Insassen des Stockes Kinder einer oder doch weniger Miitter sind. Die Einzahl der Königin im Bienenstock findet darin ihre Erklärung, dass Selectionsprocesse dadurch erheblich vereinfacht und erleichtert werden, wenn alle Nitglieder der Genossenschaft Sölne und Töchter desselben Vaters und derselben Mutter sind. Bei einem Theil der Termitenarten ist es nach den Untersuchungen ron Grassi heute noch cbenso, bei Calotermes flavicollis ist nur eine ächte Königin vorhanden, und wenn bei Termes lucifugus eine solche regelmässig zu fehlen schcint und durch sogenannte Substitutionsweibchen ersetzt wird, so ist das ein secundärer Zustand, der aus jenem anderen sich erst hervorgebildet hat, nachdem die Differenzirung der Kasten längst schon erfolgt war. Auch heute entstehen noch

1) G. Wolff, „Beiträge zur Kritik der Darwin'schen Lehre", Biolog. Centralblatt v. 15. Sept. 1890. 
ächte Königinnen bei Termes lucifugus, aber sie gründen keinen Staat mehr, sondern fliegen zur Hochzeit aus und gehen zu Grund.

Doeh ieh habe mieh schon zu lange bei den staatenbildenden Insecten aufgehalten und kehre zuriuek zu dem Punkt, dessenthalben ieh auf sie eingegangen bin. Ich wollte zeigen, wie die Natur äussere Einflüsse vielfaeh als auslösende Reize verwendet, wenn es darauf ankommt, versehiedene Entwieklungsmögliehkeiten zweckmässig zu reguliren. Nieht immer aber gibt ein äusserer Reiz den Anstoss zur Formänderung, es kann aueh ein innerer sein. So seheinen bei manehen Thieren mit Generationswechsel innere Normirungen die Aufeinanderfolge der versehiedenen Formen zn bestimmen; wenigstens konnte ieh seiner Zeit beim Generationsweehsel der Daphniden experimentell nachweisen, dass Temperatur und Austroeknen des Wassers nieht im Stande sind, bei gewissen Arten die zweigesehleehtliehe Fortpflanzung hervorzurufen ${ }^{1}$ ). Die versehiedenen Arten dieser kleinen Süsswasserbewohner sind so eingeriehtet, dass eine jede Art eine ziemlich genau bestimmte Zahl von Jungferngenerationen hervorbringt, und damn erst Männehen, und die Zahl dieser Generationen ist bei jeder Art derart normirt, wie es für die Erhaltung derselben am zweekmässigsten ist. Bei Arten, die grosse Seeen bewohnen, treten die Männchen erst am Ende des Sommers auf, dagegen bei Pfützenbewohnern, welehe der Gefalır des Austroeknens durch baldige Erzeugung ron Dauereiern be-

1) A. We ismann, ,Beiträge zur Naturgeschichte der Daphoiden", Abhandlung VII, „Die Entstehung der cyclischen Fortpflanzung bei den Daphnoiden", Leipzig 1876-1879. 
gegnen müssen, erscheinen diese und die dazu nothwendigen Männchen schon in der zweiten Generation.

Bei verwandten Krustern finden wir dagegen wieder die Zweigestaltigkeit der Art an äussere Reize gebunden. Die meisten Zoologen erimnern sich der interessanten Versuche und Beobachtungen, welche Schmankewitsch vor zwanzig Jahren ${ }^{1}$ ) mit der Artemia Mühlhausenii anstellte, einem Bewohner der salzreichen Wassertiimpel an den Küsten der Krim. Die geröhnnliche Art Artemia salina macht gewisse Veränderungen durch, die sie als A. Mühllausenii erscheinen lassen, wenn sich der Salzgelıalt des Wassers, in welchem sie lebt, allmählich verstärkt, und sie soll sich sogar in entgegengesetzter Weise veründern und in die bisher als Branchipus Schäfferi beschriebene Art umwandeln, wenn der Salzgehalt des Mediums allmälılich stark verringert wird. Die Veränderungen, welche dabei eintreten, sind, theilweise wenigstens, solche, wie sie für den veränderten Salzgehalt des Wassers rortheilhaft sind: Vergrösserung der Kiemen bei Zunahme des Salzgehaltes, entsprechend dem geringeren Sauerstoffgehalt des Wassers. Daraus möchte ich schliessen, dass der Salzgehalt nicht die directe Ursache der Abänderung ist, sondern nur der aus. lösende Reiz, der eine durch Selection entstandene Anlage zur Entfaltung anregt. Es wäre also hier, ähnlich wie bei den Bienen und Ameisen, eine doppelte oder sogar vielleicht mehrfache Anpassung des Körpers an verschiedenen Salzgehalt in Folge langsamer periodischer Schwankungen des-

1) Sehmankewitseh, "Ueber das Verhältuiss der Artemia salina Milne Edw. zur Artemia Mïhlhausenii Milne Edw. und das Genus Branchipus Schaeff." Zeitschr. f. wiss. Zool., Bd. XXV. 1875. 


\section{$-46-$}

selben eingetreten, gewisse Determinanten hätten sich in dem einen Id hohem Salzgehalt angepasst, in dem zweiten niederem, in einem dritten vielleicht mittlerem Salzgehalt, und zugleich mit diesem Polymorphismus hätte sich eine besondere Rizempfindlichkeit dieser Anlagen für verschiedenen Salzgehalt des Mediums ausgebildet, so dass immer die richtige Anlage rom Salzgehalt selbst ausgelöst wird.

Ob es sich wirklich so verhält, oder ob etwa und wieweit doch auch directe Wirkung des Salzgehaltes durch das Mittel der Intraselection mitwirkt, lässt sich nach den vorliegenden Versuchen nicht entscheiden, und ich führte den Fall nur an, um darauf hinzuweisen, dass die gewöhnliche Auslegung desselben als directe Wirkung keineswegs selbstverständlich ist, sondern dass recht wohl auch der Salzgehalt des Mediums hier bloss als Auslösungsreiz gedacht werden kann.

Ueberhaupt beanspruche ich nicht, mein Thema erschöpft zu haben; ich wollte nur an einigen Beispielen zeigen, wie ich mir denke, dass äussere Einflüsse zur Auslösung bestimmter Keimesanlagen von der Natur verwerthet werden. Der Gegenstand ist noch zu neu, als dass sich heute schon sagen liesse, welche Einwirkungen auf die Organismen alle als auslösende Reize von Doppelanlagen Verwendung gefunden haben. A priori aber müssen wir jede Art der Einwirkung dazu fähig halten, unter Umständen als Regulator der vorgesehenen Entwicklung benutzt zu werden. Wie fcin die Reizempfänglichkeit der Theile abgestuft und normirt werden kann, sehen wir ja schon an der Thatsache der allmählichen Differenzirung des Körpers der Thiere und Pflanzen nach dem Princip der 
Arbeitstheilung, denn mit der morphologischen Differenzirung ist dabei die immer feiner sich abstufende und differenzirende Reizempfänglichkeit Hand in Hand gegangen. Wie wunderbar aber diese sich verfeinern kann, das sehen wir nicht nur an allen möglichen specialistischen Leistungen der Elemente unseres Körpers, sondern an zahlreichen Vorgängen aller Art bei Thieren und bei Pflanzen. Wenn wir beobachten, dass im Allgemeinen Sclbstbefruchtung bei den Phanerogamen rermieden wird, und dass eine Menge verwickelter Einrichtungen an den Blumen dieselbe zu verhindern da sind, ja dass die ganze Existenz vieler Blumen darauf beruht, dass Kreuzung durch Insecten vortheilhaft war, so setzt dies voraus, dass sowohl Selbstbefruchtung stets möglich, als dass sie stets minder crfolgrcich wäre. Beides trifft aber nicht allgemein zu, sondern wir finden alle möglichen Grade der Empfäinglichkeit für den eigenen Pollen. Blumen, die, wie viele Ordideen, ganz auf die Kreuzungsvermittelung der Insceten angeriesen sind, haben sich als völlig fruchtbar mit dem eigenen Pollen erwiesen, andere dagegen, die, wie Corydalis cava, sehr leicht sich selbst bestäuben könnten, sind mit eigenem Pollen völlig unfruchtbar, und dem gegenuiber stehen die kleistogamen Blüthen, die sich nie öffnen und also ganz auf Selbstbefruchtung angewiesen sind. Am auffallendsten abcr tritt die verschiedene Empfindlichkeit für minimalste Reizunterschiede bei den di- und trimorphen Bliithen hervor, welche so eingerichtet sind, dass niemals Selbstbefruchtung eintritt, und zwar dadurch, dass nur der Pollen einer bestimmten anderen Form ron Blume in die Narbe mit Erfolg eindringen kann. Hier scheint man auch in die Mittel Einsicht zu haben, mittelst deren diese Anpassung erreicht 
worden ist: die Pollenkörner sind verschieden dick, und zwar entspricht ihre Dicke der Länge des Griffels jener anderen Blumenform und damit zugleich der Länge des zu treibenden Pollenschlauchs. In den meisten anderen Fällen können wir noch nicht in den Mechanismus der Reizempfänglichkeit hineinsehen, und in den meisten wird er auch ein bedeutend feinerer sein. Aber ein Mechanismus muss es immer sein, und sein Zustandekommen kann nur auf dem einzigen Princip beruhen, welches wir für das Zustandekommen von Zweckmässigkeiten kennen: Selection auf Grundlage der individuellen Variation.

Ich komme zum Schluss. Soll ich kurz das Wesentliche zusammenfassen, so hat sich gezeigt, dass äussere Einwirkungen nicht bloss in der längst bekannten Weise als Reize wirken, indem sie die Functionen des Körpers auslösen, sondern noch in einer mehr verborgenen Art. Sie werden von der Natur - so zu sagen - dazu benutzt, um das Auftreten der verschiedenen Formen, in denen eine Art erscheinen kann, zweckmässig zu reguliren. Der Keim enthält dann die Anlagen dieser mehrfachen Formen nebeneinander in sich, und cin Reiz, sei es die Art der Ernälırung oder des den Körper treffenden Lichtes oder der Wärme oder sonst einer äusseren Einwirkung - dient frïher oder später als Auslösung einer dieser Anlagen, gibt also die Entscheidung, welche von diesen Anlagen zur Entwicklung kommen soll. Die Anlagen selbst kömnen dabei in sehr verschiedenem Grade von einander abweichen, von blossen Unterschieden der Färbung und Zeichnung, wie im Falle des adaptiven Saison-Dimorphismus, den ich für Schmetterlinge und Raupen wahrscheinlich zu machen 
suchte, bis zu den tiefgreifenden Unterschieden, welche zwischen den Kasten der staatenbildenden Insecten bestehen.

In allen diesen Fällen ist die äussere Einwirkung niemals die wirkliche Ursache der Verschiedenheit, sondern sie spielt nur die Rolle des Reizes, der darüber entscheidet, welche der vorhandenen Anlage zur Entwickelung gelangen soll. Die wirkliche Ursache aber liegt immer in vorgebildeten Veränderungen der Anlagen des Körpers selbst, und diese - da sie stets zweckmässige sind - können in ihrer Entstehung nur auf Selectionsprocesse bezogen werden. Auch wenn der Schein dafuir spricht, dass di recte Wirkung äusserer Einflüsse eine solche zweckmässige Abänderung hervorrufe - genaue Untersuchung ergibt, dass es ein falscher Schein war, und dass in Wahrheit der äussere Einfluss doch nur als Reiz auf die Anlage einer vorgebildeten Anpassung wirkte. Dies hat sich in besonders schlagender Weise bei der Sterilität der Arbeiterinnen von Bienen und Ameisen gezeigt; sie ist nicht die directe Folge schlechterer Ernährung, sondern die Folge einer durch Selection hervorgerufenen Anlage eines rudimentären Ovariums, welche in demselben Ei neben der Anlage eines vollständigen Ovariums vorhanden ist, und welche zur Entwicklung kommt, wenn die junge Larve schlechter ernälırt wird: minderwerthige Ernälırung wirkt für sie als auslösender Reiz.

Grade dieser Fall hat noch ein besonderes Interesse, indem er den Forschern, welche immer noch an der Vererbung erworbener Eigenschaften und damit zugleich an dem Entwicklungsprincip Lamarck's festhalten möchten, von Neuem zeigt, dass ihre Ansicht nicht die richtige sein 
kann. Nicht in einem einzigen - und so auch nicht in diesem - von einem der Ihrigen mit so grosser Sicherheit geltend gemachten Fall hat sie sich als haltbar erwiesen. So sehe ich mich denn durch die hier vorgebrachten Thatsachen und Erwägungen nur von Neuem bestärkt in der schon lange vertretenen Ueberzengung, dass Selection allein das leitende und führende Princip bei der Entwicklung der Organismenwelt war und bis auf unsere Tage noch immer ist. 


\section{ZUSÄTZE.}



Zusatz 1 (zu p. 3). Die Reizbewegungen der tropischen Leguminosen-Blätter sind zwar schon fruiher, besonders auch ron Charles und Francis Darwin, in vortrefflicher Weise untersucht worden, aber sicheren Aufschluss iiber die biolngische Bedeutung derselben haben doch erst die neuesten Untersuchungen ergeben, die in den Tropen selbst, unter den natiirlichen Lebensbedingungen dieser Pflanzen angestellt wurden. Stalil sowohl als Haberlandt haben einen Aufenthalt in der botanischen Station zu Buitenzorg auf Java dazu beuutzt, um auch iiber diese Frage neues Licht zu verbreiten. Nach ihren Erfahrungeu liegt der Nutzen des Zusammenklappens und sich Anfrichtens dieser fiederspaltigen Blätter wesentlich mit in der dadurch erreichten Abschwächung der Gewalt der tropischen Regengiisse; auf der anderen Seite aber auch in der Regulirung der auf sie fallenden Liclitmasse, indem sie bei steigender Insolation sich immer höher emporrichten bis zum vollständigen Zusammenklappen. So verhält es sich wenigstens bei zahlreichen dieser Leguminosen der Tropen, bei welchen nicht Stossreize die Bewegung auslösen, sondern eine bestimmte Intensität der Belichtung, und bei welchen neben dem Schutz gegen die Wucht der fallenden

Vergleiche: Stahl, „Regenfall und Blattgestalt, ein Beitrag zur Pflanzenbiologie", Extrait du Jardin Botanique de Buitenzory, Vol. XI, 1893 und $\mathrm{H}$ aberlandt, "Eine botanische 'Tropenreise", Leipzig 1893, p. 112 und 113. 
Regentropfen das Zusammenklappen der Blätter zugleich auch ein Schutz gegen allzu starke Belichtung ist; die Blätter schliessen sich sowohl bei starker Belichtung als bei ganz schwacher, und diese letztere Anpassung wird von Haberlandt als eine Einrichtung erkannt, welche noch vor dem Eintritt des Regens die Blätter zum Schliessen bringt, denn vor Eintritt des Regens umdiistert sich der Himmel in der Regel so bedeutend, dass diese Schwankung in der Beleuchtungsstärke ausreicht, um die „Schlafbewegung“ der Fiederblättchen auszulösen.

Zusatz 2 (zu p. 4). Womöglich noch klarer liegt die Sache beim Geotropismus, denn hier besteht kein Zweifel, dass die Eigenschaft der Pflanze, anf die Wirkung der Schwere in irend einer. Weise zu reagiren, keine allgemeine und primäre Yflanzeneigenschaft sein kann. Eine im Wasser frei rotirende Volvoxcolonie ist gewissermassen ein lebender Klinostat, und ihre einzelnen Zellen werden von der Anziehung der Erde nicht beeinflusst. Die geotropische Empfindlichkeit der Pflanzen wird also erst entstanden sein, als dieselben sich im Boden befestigten, und sie kann somit auch in ihrer allgemeinsten Gestalt schon als Anpassung begriffen werden. Noch melır freilich tritt dies hervor, wenn wir sehen, dass die heutigen Pflanzen in ihren einzelnen Theilen eine völlig verschiedene Empfindlichkeit fuir den Reiz der Schwerkraft besitzen, dass nicht nur die Wurzel positiv, der Stamm negativ geotropiseh sein kann, sondern dass auch jede der Nebenwurzeln und jeder der Nebenäste in einem andern und genau bestimmten Winkel von der Hauptwurzel und dem Hauptstamm sich abzweigt, und dass auch dieser Winkel, bis zu einem gewissen Grade wenigstens, als eine Reaction auf den Reiz der Schwerkraft aufzufassen ist. Es kann also die geotropische Reizbarkeit der Pflanze, gerade so wie die Lichtempfindlichkeit ihrer verschiedenen Theile, sich in ganz entgegengesetztem Simne äussern, und - was noch mehr ist - diese Reizbarkeit ist für jeden Theil besonders regulirt, und zwar in solcher Weise, dass die Pflanze dadurch in den Stand gesetzt wird, 
sich wechselnden Bedingungen in vortheilhaftester Weise anzupassen. Eine Reactionsweise aber, welche denselben Reiz in verschiedenen Theilen in ganz verschiedener Weise beantwortet, kann nicht eine ursprïngliche, gewissermassen primäre Eigenschaft der Pflanze sein, sie kann nicht von jeher allen Pflanzen eigenthiimlich gewesen sein, sondern ist eine Anpassung an die Befestigung der Pflanze im Boden, und die feinsten "molekiilaren" Structuren, auf welche diese wunderbare Empfindlichkeit zu beziehen ist, können nicht auf der directen Wirkung äusserer Reize, sondern nur auf ihrer indirecten Wirkung, d. h. auf Selectionsprocessen beruhen.

Zusatz 3 (zu p. 16). Dass das Princip der Intraselection bei den Pflanzen ebenso wirksam ist, wie bei den Thieren, geht nicht bloss aus allgemeinen Erwägungen hervor. Erst kuirzlich hat Vöch ting Versuche beschrieben, bei welchen sich Pflanzen, die unter schwacher Belichtung gehalten wurden, zuerst stark von dieser beeinflusst zeigten, z. B. viel kleinere Bliithen hervorbrachten, als gewölmlich, später aber sich an die abnorme Belichtung "anpassten“ und num Blithen von normaler Grösse entstehen liessen. Diese „Anpassung" könnte vielleicht auf Intraselection zu beziehen sein. (Vergl. Vö chting "Ueber den Einfluss des Lichtes auf die Gestaltung und Anlage der Blithen ". Berlin 1893, p. 11.) Ausserdem fallen anch alle die verschiedenen Anpassungen der Pflanzentheile an die speciellen, sie treffenden Einwirkungen der Schwere, des Lichtes, der Feuchtigkeit und der chemischen Reize mit unter den Begriff der Intraselection. Ererbt ist die feinste Reizempfindlichkeit des betreffenden Gewebes nnd Protoplasma's; durch den Kampf der Theile aber erfolgt die specielle Anpassung an die gerade stattfindenden Verhältnisse, z. B. die im Text schon erwähnte Anschmiegung der Gestalt eines Baumes an die Liicke zwischen den iibrigen Waldbäumen, das starke Wachsthum an der Lichtseite, das Zuriickbleiben der Triebe an einer stark beschatteten Seite u. s. w.

Zusatz 4 (zu p. 7). Willuelm Roux, „Der Kampf der Theile im Organismus", Leipzig 1881. In dieser 
grundlegenden Schrift wird neben der Spongiosa der Knochen hauptsächlich auch die Gestalt und Verzweigung der Blutgefässe bei den Wirbelthieren besprochen und nachgewiesen, dass sie höchst zweckmässigen mechanischen Principien folgen. so dass z. B. das Lumen eines Blutgefässes an seinem Ursprung aus einem Stamm nicht die gewöhnliche cylindrische Gestalt besitzt, die es in scinem weiteren Verlauf annimmt, sondern eine konische Gestalt, genau so, wie sie ein „frei aus einer seitlichen runden Oeffnung im Stamm ausspringender Strahl zufolge der in ilum wirkenden hydraulischen Kräfte" annehmen wiirde. Diese Gestalt ändert sich bei den Blutgefässen je nach dem Winkel, den der Ast mit dem Stamm macht, und je nach dem Grössen-Verhältniss der beiden Gefässe. Die Folge ist eine möglichst geringe Reibung des circulirenden Blutes an der Gefässwandung, und bei der ungeheuren Zahl der Verästelungsstellen der Blutgefässe im Körper werden wir darin eine bedeutungsvolle Einrichtung erkennen miissen, welche wesentlich dazu beträgt, dass „der Betrieb der Circulation mit einem Ninimum ron lebendiger Kraft und ron Wandungsmaterial" ermöglicht wird.

Zusatz $5 \quad(z u$ p. 17). Siehe F. Merrifield, "The colnuring of Chrysophanus Phlaeas as affected by temperature" in "The Entomologist", December 1892 und December 1893. Die Resultate, welche dieser gewissenhafte Beobachter erzielt hat, stimmen sehr gut mit denen iiberein, welche ich an demselben Schmetterling erhielt und in Kiirze in meinem Buche "Das Keimplasma, eine Theorie der Vererbung", Leipzig 1892, p. 524 mittheilte.

Vielleicht darf ich bei Erwähnung der werthvollen Untersuchungen Merrifield's auf einen Mangel vieler englisch geschriebenen biologischen Schriften aufmerksam machen, der im Interesse solcher Untersuchungen selbst geändert werden sollte. Ich meine die Temperaturangaben in Graden der Fahrenheit'schen Scala! In Physik und Chemie hat man sich längst dahin geeinigt, nur noch die 100 theilige Scala zu rerwenden, und es wäre ein grosser Fortschritt, wenn 
anch die Biologen Englands und Amerikas desgleichen thum wollten. Die Angaben in Falırenheit-Graden lassen sich nur mit Miihe in Celsius-Grade übertragen: sie sind geradezu eine Erschwerung des Verständnisses fïr den nicht daran gewölnten Leser.

Dass es sich bei Polyommatus Phlaeas wirklich um directe Wirkung der 'Temperatur handelt und nicht um irgend eine Anpassung, geht auch aus den Beobachtungeu Fritze's herror, der im heissesten Theil des süljapanischen Sommers diese Art fast ganz schwarz fand. (F ritze, „Ueber Saison-Dimorphismus und Polymorphismus bei japanischen Sclmetterlingen". Berichte der naturforschenden Gesellschaft zu Freiburg i. B. VIII. Bd. 1894; 1, 152-162.

Zusatz 6 (zu p. 19). Dass wirklich ein zeitlicher Dimorphismus, der auf Anpassung berult, also ad aptiver Saison-Dimorphismus, rorkommt, das möchte ich auch aus einer Bemerkung des vielgereisten und vielerfahrenen Schmetterlingskemers I) $r$. Adalbert Seitz vermuthen. Derselbe erzïhlt in seinn selur hïbschen und anregenden "Reiseskizzen" (Stett. ent. Zeit. 1893, p. 27), dass in Japan auf den Hügeln bei Jokohama im November noch zahlreiche Falter fliegen, deren „Unterseite blattartig ist, was um so auffälliger ist, als die dazu gehörige Sommergeneration dies nicht hat; man hat daher die Herbstform von Grapta C. aureum als Gr. Pryeri besclurieben und Terias Laeta und Jaegeri, die beide nur saisondimorphe Generationsformen sind, lange für getrennte Arten gehalten". Der Verfasser erkliirt diese Anpassung dadurch, dass zu dieser Jahreszeit das grïne Laub "bis auf spärliche Reste" verschwunden ist, dagegen der Boden voll von diirren Blättern liegt. Es wiirde interessant sein, diese gelegentliche Andeutung genauer zu rerfolgen, und zwar würde dabei nicht nur festzustellen sein, wie stark und wie constant die Unterschiede der beiden Generationen sind, sondern vor Allem auch iln biologischer Werth. Denn wo Zweigestalt auf Züchtungsprocessen beruht, ist eben jede der beiden Formen Anpassung und 


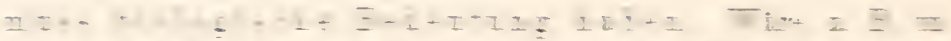

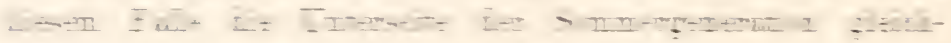

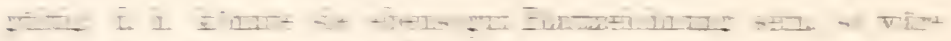

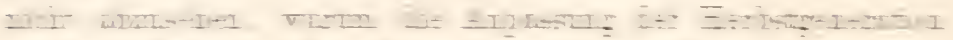

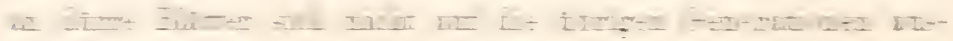

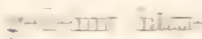

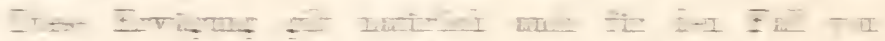

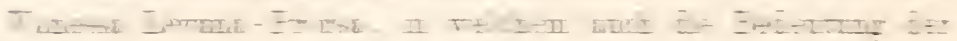

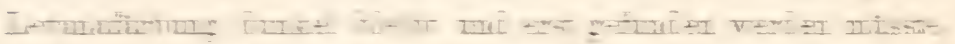

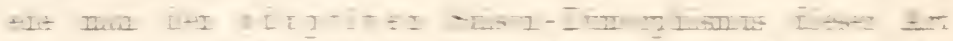

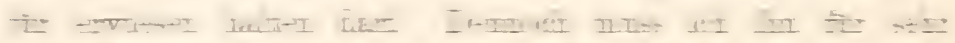

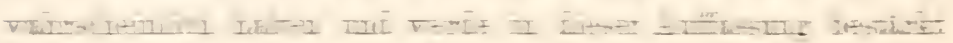

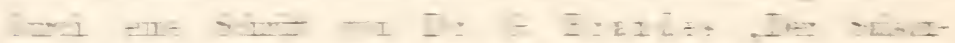
-

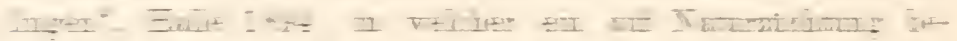

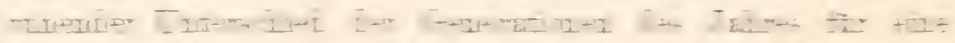

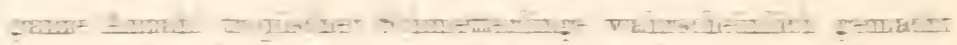

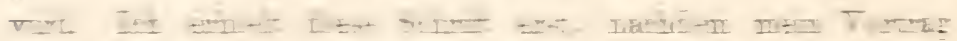

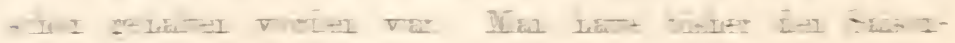
ju $L=$ -

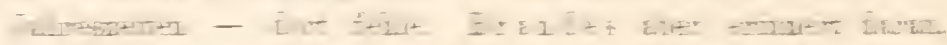

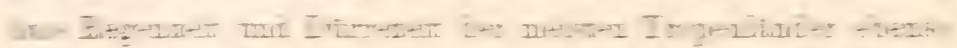

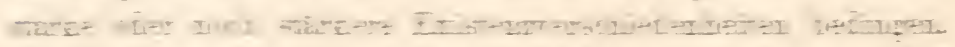

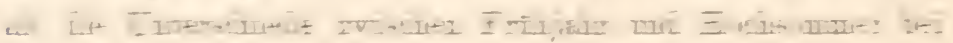

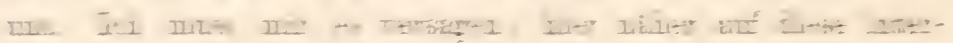

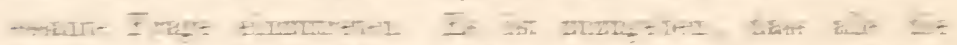

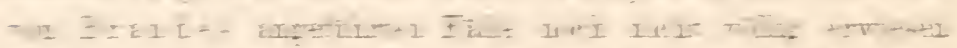

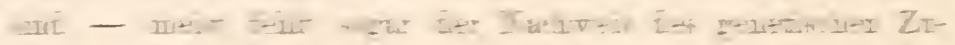

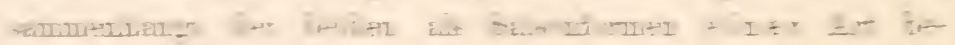

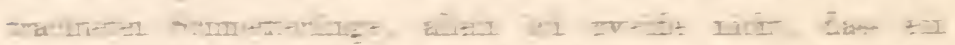

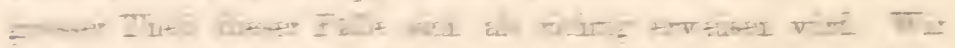

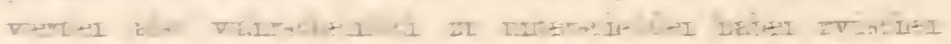

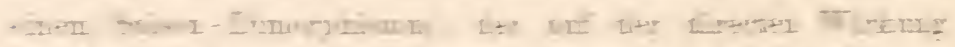

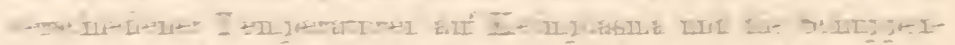
a. 


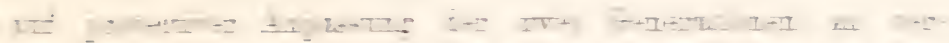

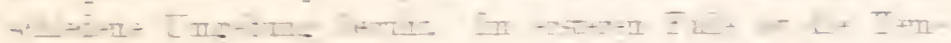

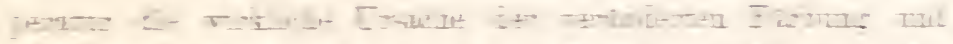

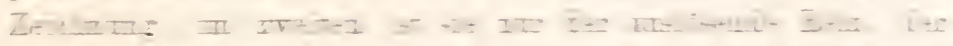

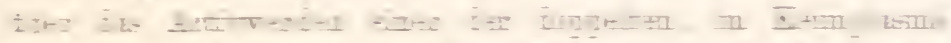

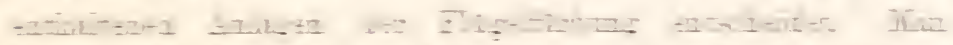
I.

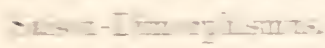

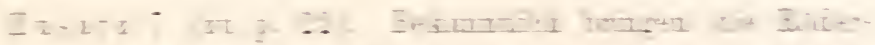

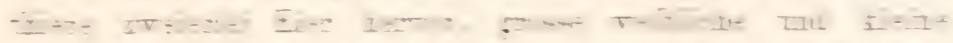

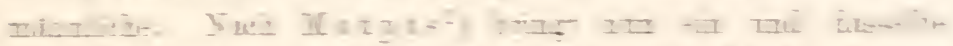

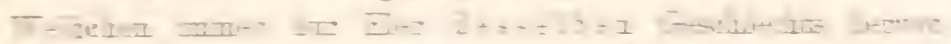
L- - IV

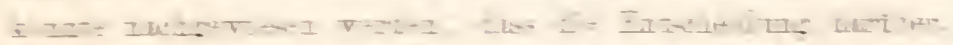

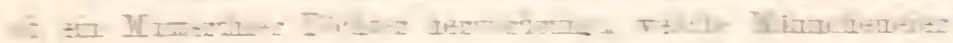

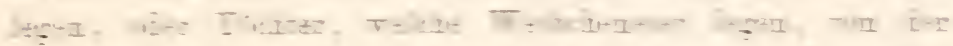

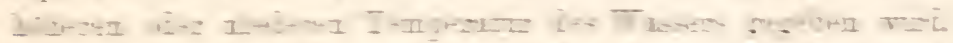
I

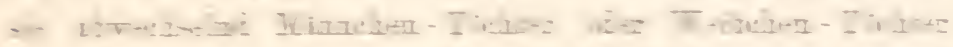

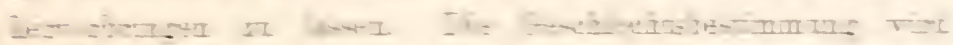

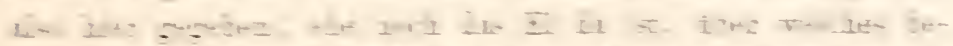

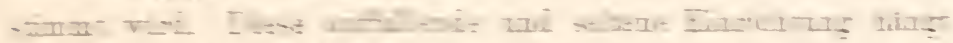

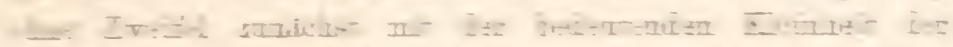

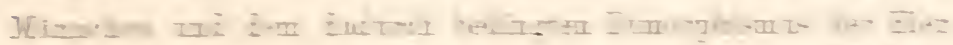

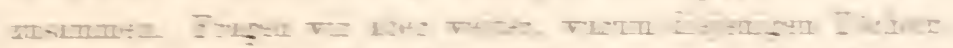

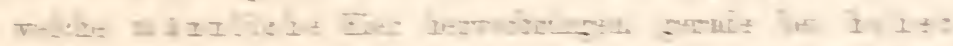

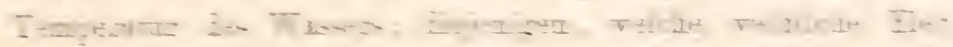

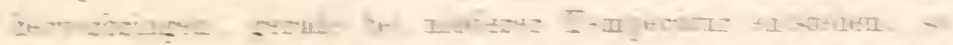

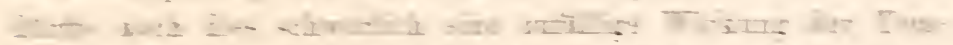

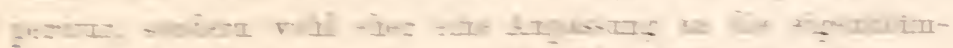

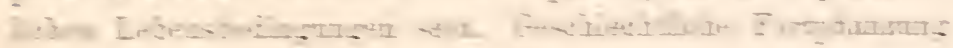

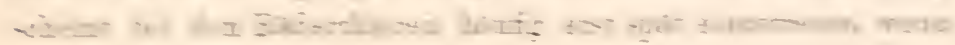

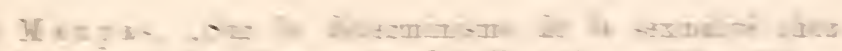
Iy 
die Colonie schon beinahe die Höhe ihrer Entwicklung, d. h. die grösste Individuenzahl erreicht hat. Dies wird aber meistens zusammenfallen mit der höchsten Wasserwärme, so dass also durch die erwähnte Einrichtnng erreicht würde, dass die Männchen zu rechter Zeit auftreten. Ist diese Auslegung die richtige, so wïrden wir begreifen, warum in diesem Falle die Geschlechtsbestimmung von der Wärme, und warum in dieser Weise abhängig gemacht wurde.

Zusatz 8 (zu p. 23). Watasé hat in einer 1892 erschienenen Schrift "On the Phenomena of Sex-Differentiation" den Geschlechtsunterschied selbst als eine Reizerscheinung aufzufassen gesucht, wenn ich ihn recht verstehe, etwa vergleichbar dem positiven und negativen Bild ein und desselben Gegenstandes. Eine solche Auffassung liegt mir fern, wie ans dem weiteren Verlauf des Vortrages wohl dentlich genug hervorgeht. (S. Journ, of Morpholngy, Vol. VI, Boston 1892.)

Zusatz 9 (zu p. 26). Die hier in kurzem Auszug mitgetheilten Versuche mit Musea vomitoria sind iu den Jahren 1884 und 1885 angestellt und noch nicht veröffentlicht worden, weil ich die Absicht hatte, sie noch nach anderer Richtung hin fortzusetzen.

$\mathrm{Zusatz} 10$ (zu pr. 26). Meine normal gefiitterten Fliegenlarven brauchten ebensoviel Zeit zu ihrer Entwicklung bis zur Verpuppung, als die hungernden, nämlich 206 Stunden, und frassen nahezu fortwihrend während dieser Zeit. Den Hungerlarven wurde nur 138-150 Stunden Fresszeit gewährt, also nur ${ }^{6} / 10--^{-7} / 10$ der normalen Ernährungsdaner. Der Unterschied in der Erlührung kommt aber in diesen Zahlen nur zu einem sehr unvollkommenen Ausdruck; er ist in Wirkhichkeit bedeutend grösser, wie man sogleich zugeben wird, wenn man bedenkt, dass die hungernden Larven viel langsamer wachsen nnd viel kleiner bleiben, d. h. also zu jeder Zeit der 138 oder 150 Stunden ihres Larrenlebens weniger Nahrung aufzunehmen fähig waren, als wenn sie die dem Stadium zukommende normale Grösse besessen hätten. 
Zusatz 11 (zu p. 31). Ich habe dieses Verhalten der Daphnideneier damals - und wohl nicht mit Unrecht dahin gedeutet, dass die Eier sich zu Gunsten der Erhaltung des Thieres selbst auflïsen, und jedenfalls ist dies der Erfolg ihrer Auflösung, wenn auch vielleicht kein beabsichtigter, sondern ein unvermeidlicher. Wie sehr aber die Reifung der Eizellen von der Ernährung abhängt, das lehrten auch meine Fliegen. Ich hatte die Versuche damit begonnen, zu erproben, ab die Thiere sich überhaupt in Gefangenschaft fortpflanzen, was von vornherein nicht vorauszusagen war, da viele Insecten, z. B. alle Tagschmetterlinge, dies nicht thun. Und in der That schien es anfänglich auch hier so zu sein, dem trotz reichlicher Ernährung mit Rüben und Zucker verging iiber ein Monat, ohne dass Eier abgelegt wurden. Als ich den Thieren aber dam ein Stỉck Fleiscl in den Zwinger legte, stiirzten sich alle darauf und sogen den Saft desselben begierig ein. Einen förmlichen Fleischhunger zeigend, bedeckten sie das Stiick dicht gedrängt, und die Folge war, dass sie schon eine Woche später eine grosse Menge von Eiern ablegten.

Es hatte den Thieren also an stickstoffhaltiger Substanz gefehlt, ohne die sie ihre Eier nicht zur Reife bringen können, denn frisch aus der Puppe geschlïpfte Fliegen haben zwar vollkommene Ovarien, aber immer winzig kleine. Als ich später meine Fliegen von Anfang an mit Zucker und Fleischsaft fiitterte, so entwickelten sich die Eier in den Ovarien enorm rasch, so dass die erste Eiablage schon zehn Tage nach dem Ausschliipfen eintrat.

Man sieht daraus, dass die Larvennahrung, so reichlich sie auch ist, bei diesen Fliegen doch nur dazu reicht, die Eierstïcke a nzulegen, nicht aber auch schon einen Theil der Eizellen der Reife nahe zu bringen, und ebenso scheint es bei den Bienen und Ameisen zu sein. Reichliche Ernährung im Imagozustand ist deshalb unerlässlich, wemn die Eizellen reifen sollen, und damit wird es zusammenhängen, dass die Arbeiterinnen der Bienen und Ameisen gewöhnlich keine Eier zur Reife bringen, demn sie müssen sich gewöhnlich selbst er- 
nähren und dabei stark arbeiten, während die Königinsen auch im Imagozustand reichlich gefüttert werden. Tritt aber ausnahmsweise einmal auch bei den Arbeiterinnen reichliche Ernährung und erhöhter Stoffwechsel ein, dann bringen auch sie die paar Eikeime ihrer wenigen Eiröhren zur Reife und legen Eier. So möchten wohl die Versuche Wasmann's zu erklären sein, der nach künstlicher Erhöhung der Wärme vielfaches Ablegen von Eiern bei seinen Ameisenarbeiterimen, und zwar bei melıreren Arten beobachtete ${ }^{1}$ ). Die Wärme wird Erhöhmg und Beschleunigung des Stoffwechsels und dadurch auch Verstärkung des Appetites bewirkt haben. Uebrigens gelang der Versuch bei verschiedenen Arten in verschiedenem Grade, was erklärlich ist, wenn man bedenkt, dass die Ovarien anch in verschiedenem Grade verkiimmert sind. Wenn sie, wie bei Tetramorium caespitum, gar keine Eiröhren mehr enthalten, damn kann auch die reichlichste Ernährung keine Eiproduction mehr herbeiführen.

Zusatz 12 (zu p. 35). In meinem Buche „Das Keimplasma", Jena 1892, habe ich bloss von doppelten oder mehrfachen Determinanten gesprochen als der idioplasmatischen Wurzel des Di- und Polymorphismus. Ich stellte mir die Entstehung eines solchen Dimorphismus derart vor, dass zuerst eine Verdoppelung der betreffenden Determinanten eines Ids einträte und dann ihr Variiren nach verschiedener Richtung. Ein nochmaliges Durchdenken der vorliegenden Thatsachen lässt mich heute die hier vertretene Modification für zutreffender halten. Der constitutionelle Dimorphismus einer Art - auch der sexuelle - erklärt sich leichter durch die Annahme, dass dis homologen Determinanten in dem einen Id in anderer Weise abändern, als in dem anderen; so diss also z. B. das eine Id mämnliche, das andere weibliche Determinanten der Keimdriise, der Geschlechtswege, der Flügelfürbung etc. ent-

1) E. Wasmann, S. J. "Parthenogenesis bei Ameisen durch kuinstliche Temperaturverhältnisse". Biolog. Centralblatt, Ril. XI, Nr. 1. 1. Februar 1891. 
hält. Ebenso denke ich mir jeden anderen Di- oder Polymorphismus durch rerschiedenartiges Abändern der entsprechenden Determinanten der verschiedenen Ide entstanden. Nur der zeitliclue Dimorphismus, insoweit er nur auf der directen Wirkung :iusserer Einflüsse berult, setzt keine Verschiedenheit der Ide des Keimplasmas roraus. Man rergleiche: "Das Keimplasma" p. $495-497$.

Diese Abänderung hat offenbar den Vorzug grösserer Einfachheit, insofern sie nicht der Hypothese einer dem verschiedenartigen Abandern der betreffenden Determinanten vorausgehenden Verdoplelung bedarf, einer Hypothese, die, wie ich friher schon sehr wohl empfunden hatte, nicht gut motivirt werden kann. Sie gestattet weiter eine ganz allmähliche $\mathrm{Zu}-$ nahme der Id-Differenzen bis zu vollständiger Terschiedenheit sämmtlicher Determinanten des Ids, so dass also daun zwei oder mehr wesentlich rerschiedene Id-Arten das Kieimplasma zusammensetzen, und schliesslich - wenn nöthig — selbst eine 'Trennmo' derselben in zwei Gruppen stattfinden kann, wie sie bei den Arten mit männlichen und weiblichen Fiem thatsächlich stattgefumden haben muss.

Es gewihht aber diese Auffassung auch einen tioferen Einblick in die Ursachen der Geschlechtsbestimmung. Sobald es besondere männliche und weibliche Ide gibt, so wird die Anzahl derselben unter Umstanden entscheidend dafür sein, ob der sich entwickelnde Organismus weiblich oder männlich ausfällt. Denn wenn es auch für manche Fälle wahrscheinlich oder selbst gewiss ist, dass das Geschlecht durch äussere Einfliisse bestimmt wird, die das Ei treffen, so wird man sich das doch nicht als die einzige, ja wohl nicht eimmal als die Hauptentscheidung in allen Fiallen zu denken haben, sondern es sind das Anpassungen an besondere Lebensverhältnisse. Gerade beim Menschen tritt es ja selur augenfällig hervor, dass das Geschlecht auch anererbt sein kann in gewissem Sinne; ich meine, dass die Bestimmung des Geschlechts durch die Zus ammensetzung des Keimes selbst gegeben wird. Wie viele Familien bringen vor- 
wiegend männliche oder weibliche Kinder hervor, und das dürfte schwerlich in irgend welchen äusseren Einflüssen seinen Grund haben. Wenn wir aber das Keimplasma aus männlichen und weiblichen Iden zusammengesetzt denken, dam kann zwar das Zahlenverhältniss derselben gleich sein, also wie $1: 1$ sich verlalten, aber es werden auch Abweichungen davon vorkommen, die durch Reductionstheilung und Amphimixis noch einseitig verstärkt werden können, und die, wenn sie eine gewisse Hölıe erreichen, dazu fïhren können, jedem Kind desselben Elternpaares oder doch den meisten das gleiche Geschlecht zu vindiciren. Ich hoffe, dies an einem anderen Ort näher ausführen zu können.

Diese Anschauung von mehr oder minder stark verschiedenen männlichen und weiblichen Iden, als idioplasmatischer Wurzel des sexuellen Dimorphismus, lässt sich ganz wohl auch mit der gelegentlichen Bestimmung des Geschlechtes durch äussere Einfliisse vereinigen. So gut als die ArbeiterIde der Biene durch minderwerthige Larvenernährung activ werden, während die Königinnen-Ide inactiv bleiben, lässt es sich als möglich denken, dass beim Frosch intensive Ernährung der Larven vorwiegend die weiblichen Ide activ werden lasse, schwache Eruährung aber vorwiegend die männlichen, oder dass bei der Biene irgend ein mit dem Act der Befruchtung zusammenhängender Factor das Activwerden der weiblichen Ide hervorrufe.

Zusatz 13 (zu p. 30). Es ist mir nicht unbekannt, dass die pathologische Anatomie Missbildungen kennt, welche in dem Ausfall eines Organs oder Körpertheils bestehen; solche Fälle bilden aber keine Widerlegung der auf p. 30 ausgesprochenen Ansicht von der phyletischen Natur des Rudimentärwerdens typischer Theile. Denn wenn z. B. das Gehirn bei menschlichen Embryonen ganz oder theilweise fehlt oder abnorm klein ist, oder sich Defecte am Herzen fiuden, oder grössere oder kleinere Abschnitte der Extremitäten fehlen, so sind diese sogenannten "Aplasieen" und "Agenesieen" doch niemals aus ungenïgender Allgemein-Ernährung entstanden. 
Sie beruhen - wie $\mathrm{E}$. Ziegrler in seinem Lehrbuch der pathologischen Anatomie ausführt (Band I, p. 369) entweder auf Vererbung abnormer Keimsanlagen oder auf primären pathologischen Keimesvariationen mubckannter Herkunft und Ursache, oder schliesslich auf ässeren Schïdlichkeiten, wie z. B. Einschnirungen der embryomalen Gliedmassen durch die Nabelschnur oder die Eihäute u. s. w.

Zusatz 14 (zu p. 40). Bis ror Kurzem war es nur für die Biencn nachgewiesen, dass die weiblichen Larven durch verschiedenartige Ernälrung zu Arbeiterinnen odr Königinnen bestimmt werden. Bei ihnen kennen wir, besonders durch die sehönen Untersuchungen von v. Planta, sehr genan die Qualitait und Qnantitiat des Futters, welche die Larven verschiedener Art erhalten. Fiir die Ameisen fehlt der Beweis dafür, dagegen laben wir seit Kurzem gerade iber diejenigen staatembildenden Insecten, iiber welche noch die grösste Dunkelheit herrschte, die Termiten, sehr gute und gerade in Bezug auf diesen Punkt bestimmte Anfschliisse erhalten. Grassi ${ }^{1}$ ) in Catania hat fiu die Termiten Siciliens nachgewiesen, dass anch bei ilnen wie bei den Bienen das Ei noch die Anlage zu jeder Art von Individuen in sich enthält. Ob die Entwicklung zum Männchen anch hier durch Ansbleiben der Befruclitung bestimmt wird, musste zwar offen gelassen werden, aber es wurle festgestellt, dass auch hier die Larven der fruchtbaren Wribchen weit mehr und weit nahrumgsreicheres Futter erhalten, als die zu Arbeitern oder Soldaten bestimmten jungen Thiere. Auch könneu die Larven noch in späterer Zeit nach Willkiir zu fruchtbaren Thieren oder zu unfruchtbaren Arbeiterimen oder soldaten erzogen werden, und es ist anch hier ein nahrungsreiches Secret der 'Thiere selbst, welches die Geschlechtsthiere hervorruft. Genau wie bei den Bienen erhalten alle jungen Larven drei Tage

1) Grassi e Sandias, "Costituzione e sriluppo della Società dei Termitidi. Osservazioni sui loro costumi". C'atania 1893. Atti dell' Acad. Gioenia di Sc. nat. Vol. VI e VII. 
lang dieses Secret als Nahrung, dann aber bekommen es nur noch die zu Geschlechtsthieren bestimmten Larven, die ïbrigen nicht, oder doch in geringerer Menge. Die Reizempfindlichkeit der Larve für die verschiedene Ernährung muss aber bei den 'T'ermiten noch feiner abgestuft sein, als bei den Bienen, demn aus Grassi's Versuchen geht hervor, dass auch der Unterschied von Arbeitern und soldaten in der Willkür der fütternden Individuen liegt; nimmt man ihnen ihre Soldaten weg, so machen sie sich neue aus den vorhandenen Larven.

Zusatz 15 (zu p. 42). Herbert Spencer hat meinen Hinweis ${ }^{1}$ ) auf die Arbeiterinnen der socialen Insecten als eines Beispiels von Umwandlung einer Lebensform mit rïlligem Ansschlnss jeder Vererbung erworbener Eigenschaften dadurch zu entkrïften gesucht, dass er die Behauptung anfstellt, die Charaktere der Neutra seien schon zu einer Zeit entstanden, als alle Weibchen noch fortpflanzungsfaihig waren. Ich will nun nicht bestreiten, dass vielleicht noch einzelne Eigenschaften der hentigen Arbeiter wirklich so alten $\mathrm{Ur}^{-}$ sprunges sein können, wenn es anch schwer oder vielmehr unmöglich ist, dariber irgend welche Sicherheit zu gewinnen. Dass aber der grösste 'Theil der Arbeiter-Charaktere erst später, d. h. erst während und nach der Entstehung der Kasten, sich ausgebildet hat, scheint mir einem Zweifel nicht zu unterliegen. Herbert Spencer betrachtet die Unfruchtbarkeit als directe Folge minderwerthiger Ernährung der einzelnen Larve. Ich habe oben gezeigt, dass dem nicht so sein kam, aber nehmen wir einmal an, es sei so gewesen, wie wäre da der Instinct der heutigen Arbeiterin, als Imago viel weniger Nahrung zu sich zu nelmen, als die fruchtbaren Weibchen, entstanden? Doch nicht auch durch die schwächere Ernährung

1) Ir eismann, "Die Allmacht der Naturzichtung, eine Erwiderung an Herbert Spencer", Jena 1893 und "The AllSufficiency of Natural Selection, a reply to Herbert Spencer", Contemp. Review, Sept. u. Oct. 1893. 
zur Larvenzeit? Meine Hungerfliegen zeigten wenigstens keinen geringeren Appetit im Imago-Zustand, als ihre Schwestern, die als Larven reichlich gefittert worden waren. Oder sollte dies anch ans weit zurückgelegener Zeit stammen und die damaligen Weibchen alle nur wenig Nahrung instinktgemäss zu sich genommen haben? Dann hätten sie sich aber auch nicht fortgepflanzt, wie demn die heutigen Arbeiterinnen die paar Fizellen, welche in ihren wenigen Eirïhren enthalten sind, für gewöhnlich nicht zur Reife bringen. Und dann die doppelte, ja selbst zuweilen dreifache Form der Arbeiterinnen bei manchen Ameisen und 'Termiten, anf die ich in meinem Aufsatz schon in diesem Simn hingewiesen hatte. Aber ich kann es mir ersparen, noch weitere Widerlegungen der ganz unhaltbaren Behauptungen Speneer's vorzubringen, da Mr. Platt Ball dies in einem Aufsatz "Neuter Insects and Lamarckism" (Nat. Science Vol. IV, Febr. 1894) in schlagender Weise bereits gethan hat. Eine einzige der dort an Spencer gestellten Fragen zeigt schon die ganze Schwäche der Position des Lamarckismus: Weñn wirklich die Eigenthümlichkeiten der Arbeiterinnen nicht bei ihnen entstanden, sondern von den Vorfahren, aus der vorsocialen Zeit ererbt wären, wie käme es, dass die Königin und die Drohnen sie in jeder Generation den Arbeiterimnen ron Nenem iiberliefern können, während sie selbst dieselben doch lïngst verloren haben?

Schon vor meinem gegen Spencer gerichteten Anfsatz latte Lloyd-Iforgan in seinem gedankenreichen Bnclı "Animai Life and Intelligence" p. 213 darauf lingewiesen, dass die Soldaten gewisser Ameisen (Oedocoma ceplalotes) mit ihren colossalen Köpfen und Mandibeln Umwandlungen vieler zusammen funktionirender Theile voraussetzen, welche am nicht vererbtem Gebranch zugeschrieben werden können, da diese Soldaten steril sind. Nun würde zwar eine dialectische Vertheidigung der Vererbung erworbener Eigenschaften zu der letzten Ausflucht greifen kömnen, diese Sterilität zu leugnen. Soldaten allerdings sind woll noch nie fruchtbar gefunden worden, aber gewöhnliche Arbeiterinnen legen — 
wie schon angeführt wurde - öfters Eier. Nan könnte also sagen, dies sei nicht Ausnahme, sondern Regel; ans diesen mbefruchteten Arbeitereiern gingen die Männchen der Colonie hervor, und durch diese wiurden die durch Gebranch und Nichtgebrauch gesetzten Veränderungen auf die folgende Generation von Weibchen vererbt.

Solche Einwände sind mir privatim auch thatsächlich schon gemacht worden. Darauf ist aber zu erwidern: Erstens passt der Einwurf nicht auf die Bienen, von denen wir sicher wissen, dass die Königin zahlreiche Drohneneier legt, und zweiteus passt el nicht auf die Ameisen, weil wir unter ihnen e in e Art mindestens kennen, bei welcher die Arbeiterimnen a lle Eirïhren eingebiisst haben, also keine Eier mehr hervorbringen können. Dies könnte nicht eingetreten sein, wenn der Ameisenstaat so eingerichtet wäre, dass die Männchen von den Arbeiterimen hervorgebracht werden muissten. Der graduell zunehmende Schwund der Eiröhren bei verschiedenen Arten deutet vielmehr darauf hin, dass die Arbeiterovarien keine Bedeutung mehr fiir die Erhaltung der Art haben.

Zusatz 16 (zu p. 35). Im Vorwort habe ich schon auf ein Argument Spencer's hingewiesen, auf welches ich im Text dieses Vortrags nicht speciell eingegangen sei, weil es mir mehr auf oberflächliche Leser berechmet $z u$ sein schien, die sich nicht die Mïhe nehmen, eine ilmen umbequeme Theorie durchzudenken. Da mun aber während des Druckes dieser Schrift ein hervorragender Forscher, Oscar Hertwig, die Argumentation Spencer's aufgenommen, als eine "treffliche Widerlegung" meiner Determinantenlehre hingestellt und in ganzer Länge wieder abgedruckt hat, so will ich dennoch näher auf sie eingehen.

Es handelt sich $10 m$ die ,bei manchen Arten von Ameisen vorkommenden $Z_{w}$ ischenstufenzwischen den extremen Individuen, den fruchtbaren Weibchen und den unfruchtbaren Arbeitern". Spencer erklärt sie dadurch, dass „die Entziehung der Nahrung nicht bei allen Eiern" (doch wohl Larven!) „zur selben Zeit während 
iluer Entwickelung stattgefunden" habe ( it must lappen that the stoppage of feeding will be indefinite"), und meint dam weiter" "Somit bieten die Zwischenformen für die Theorie der unmittelbaren Bewirkung nicht die geringste Schwierigkeit. Wie kann sich aber die Determinantenlehre mit ihmen abfinden?"

"Wemn IV eis ma n u consequent sein will, "fäht S pencer fort, "muss er sagen, dass jede der Zwischenformen der Arbeiter ihre besondere Reilı von Determinanten haben muss, welche eine entsprechende Reihe von Modificationen der Organe verursacht; denn er kann nicht annehmen, dass, während vollkommene Weibchen und die extremen Arbeitertypen ihre rerschied(nen Reihen ron Ueterminanten laben, die Zwischenformen sie nicht haben. Daher werden wir zu dem sonderbaren schluss genöthigt, dass zu den deutlich unterschiedenen Reilıen von Determinanten noch, um die Zwischenformen herrorzurufen, manche andere weniger unterschiedene Reihen - ein Schock oder mehr Arten von Keimplasmen zu den vier Hauptarten - hinzukommen missen. Ausserdem fïlnt eine Ueberlegung zu dem noch viel merkwïrdigeren Schluss, dass diese zahlreichen Arten ron Keimplasmen, welche die zalllreichen Zwischenformen erzeugen, nicht nur unnöthig. sondern sogar schädlich sind, dass sie Formen erzeugen, die nicht gut angepasst sind für eine der Funktionen, die ron den extremen Formen ausgeibt werden. Die Nutzanwendung ist, rlass Naturzuchtung diese unvortheilhaften Formen geschaffen lat! Wenn aber W e is m a nn, um diesem nothwendigen Selbstmord zu entrimen, den Schluss ammimmt, dass die Verschiedenheiten zwischen den zahlreichen Zwischenformen durch beschränkte Fütterung der Larven auf verschiedenen Stadien bedingt sind, dann ist er auch zur Annalıme verpflichtet, dass die Verschiedenheiten zwischen den extremen Formen und zwischen diesen und den vollkommenen Weibchen in ähnlicher Weise rerursacht sind. 'Thut er dies, was wird dann aus seiner Hypothese, dass die rerschiedenen Kasten constitutionell verschieden und das Resultat der Wirkung natürlicher Zuchtwahl sind?" 
O. Hertwig hat dieser Kritik von spencer nur noch hinzuzusetzen, dass es sich hier um "den schon mehrfach betonten Fehler handelt, dass W e i s m a n n etwas, was als äussere Bedingung zum Entwickehungsprocess hinzutritt, in der Anlage selbst als einen ihrer Bestandtheile hinein rerlegt, also den wichtigen Unterschied zwischen Anlage und Bedingung ganz übersehen hat".

Das ist freilich sehr schlimm! aber ich bekomme ja auch meine Strafarbeit dafür, indem ich diese Entgegnung schreiben muss, die furr Jeden überfliissig ist, der an die Beurtheilung meiner theoretischen Vorstellungen, ich will nicht sagen mit Wohlwollen, aber doch mit einer gewissen Unparteilichkeit und nicht schon vornherein mit der Absicht herantritt, sie zu verurtheilen.

Auch fiir mich hat "die Natur in den polymorphen Thierstaaten gleichsam eine Reihe höchst wichtiger Experimente angestellt"; aus diesem Grund habe ich sie so in den Vordergrund der Betrachtung geriickt in Bezug auf die fundamentale Frage nach der Vererbung erworbener Eigenschaften. Nur ist die Antwort, die ich aus diesen Experimenten herauslese, eine andere, als die O. Hertwig daraus zu entnehmen meint.

Wer die Vorrede zu meinem Buch "Das Keimplasma, eine Theorie der Vererbung", Jena 1892, gelesen hat, weiss, dass ich nichts weniger als Unfehlbarkeit fur diese Theorie in Anspruch nehme. Mag sie aber noch so voll von Irrthümern sein - dass sie nicht gänzlich werthlos für den Fortschritt der Wissenschaft ist, das scheint mir doch unter Anderem gerade durch solche Fälle bewiesen zu werden, wie der von der Entstehung von Zwischenformen zwischen den Kasten der Ameisen. Sie erklärt ilın auf einfache und völlig ungezwungene Weise, wenn man einmal die Voraussetzungen zugiebt.

Wie schon im Text dieses Vortrags kurz ausgefuilurt wurde (p. 34 und f.), muss ich amnehmen, dass bei der Entstehung der Arbeiterimnen die weiblichen Ide des Keimplasma's zuerst in einigen, dann in immer zahlreicheren Determinanten anfingen abzuändern, bei dem einen Individuum rascher, bei dem anderen langsamer. Die Abänderungen waren zuerst 


\section{$-71-$}

geringfuigig, steigerten sich aber im Laufe zahlreicher Generationsfolgen und stellten sich durch Naturziichtung geleitet nach und nach immer mehr zu einem festeu Bestand eines abgeänderten Deteruinanten-Complexes fest, der zuletzt wohl s ïmmtliche Determinanten der betreffenden Ide umfasste. Zugleich wird durch denselben Regulator nach und nach eine immer grössere Gleichförmigkeit der Abänderung eingetreten sein, so dass schliesslich diese abgeänderten oder Arbeiter-Ide einander sehr ähnlich, wemn auch nie ganz gleich wurden. Dieser Zustand des Keinplasma's wiirde ungefäh. dem Zustand entsprechen, in welchem sich heute eine Ameisenart befindet, bei welcher alle Arbeiter einander vollkommen ähnlich sehen, und Zwischenformen zwischen Weibchen und Arbeiterimen nicht mehr vorkommen. Aber wie enorme Zeiträume und (ienerationsfolgen miissen vergangen sein, ehe durch die langsame Wirkung der Ausmerzung des minder Passenden diese hohe Aehnlichkeit der Arbeiter-Ide und damit der Arbeiter selbst erzielt reeden konnte! Und die ganze Uebergangszeit, vom Beginn der Umwandhung bis zu ihrem Höhepunkt, muss stets noch Keimmaterial zu verschiedenen Graden der Abweichung rom reinen Weibchentypus geboten laben, so dass Zwischenformen zwischen Arbeiterinnen und "Königimmen" zuerst äusserst lıänfig sein mussten, nach und nach aber immer seltener wurden, in dem Maasse, als die verschiedenen in einem Kéeimplasma zusanmen liegeuden Arbeiter-Ide mehr und mehr einander gleich wurden nud ilure Verhältnisszahl zu den Königinnen-Iden mehr und mehr geregelt wurde, d. h. sich auf dieselbe Zahl in allen Keimplasmen einstellte.

Zwischenformen entstehen nach meinen Voraussetzungen bei diesem Process der Umbildung so lange, als die Zusammensetzung des Keimplasma's noch die Möglichkeit bietet, dass durch Reductionstheilung und Amphimixis zwei Elternkeimlällften zur Vereinigung kommen können, d i e e ine früh he re phyletische Stufe der Arbeiterbildung in der Mehrzahl ihrer Arbeiter-Ide enthalten. Demn im 
Beginn des ganzen Entwickelungsprocesses gab es natiulich noclı gar keine scharf ausgeprägten Arbeiter, sondern nur Zwischenstufen zwischen den leutigen Arbeitern und den Königinnen. Da nun aber der Voraussetzung nach nicht in allen Iden die Veränderungen gleich stark und gleich rasch erfolgten, vielmehr jedenfalls noch unzählige Generationen hindurch in jedem Kéimplasma einzelne Ide minder stark umgewandelt waren, als andere, so miss es noch lange Zeit hindurch immer wieder vorgekommen sein, dass solche Ide durch Reductionstheilung und Amphimixis gelegentlich zu eimer Majoritait sich zusammenfanden und das betreffende Individum zu einer Zwischenform stempelten - eigentlich einer Rückschlagsform, denn die Zwischenformen waren frïher die Regel. Der ganze Fall gehört unter die Rückschlagserscheinungen und enthïlt, soweit ich sehe, nichts, was niclit aus meinen theoretischen Voraussetzungen ganz von selbst sich ergäbe. Das ron Spencer ironisch postulirte "Schock weiterer Keimplasma-Arten" existirt wenn anch in bescheidenerer Anzahl - wirklich und folgt ganz von selbst aus der theoretischen Basis, von welcher ich ausgelıe. Gerade in der Annahme vieler Ide, deren jedes seinen bis zu gewissem Grade selbstständigen Entwickelungsgang einhält, liegt eine der Hauptstärken meiner Position. Gerade dadurch erkliiren sich die oft so iiberraschenden Erscheinungen des Rïckschlags in einfacher Weise, und vor Allem auch die verschiedenen Mischungen der Charaktere beim Riickschlag, wie nachlher noch gezeigt werden wird. Spencer hätte mir eigentlich keinen besseren Gefallen thun können, als diesen seinen wenig iiberlegten Einwand zu machen.

Ich muss aber jetzt, wo man mich einmal gezwungen hat, auf die Frage näher einzutreten, noch auf manches Andere hinweisen, was mit meinen Anschaunngen harmonirt, mit denen meiner Gegner aber nicht. So sind z. B. nach den ausgedehnten Erfahrungen des scharfsichtigen Auguste Forel diese "Zwischenformen" keineswegs gleich häufig bei allen Arten, bei manchen sind sie iiberhanpt noch nicht gefunden 
worden, Wenn man nicht annehmen will, dass bei den Ameisen sich etwas ereignet liäte. was sonst im ganzen Thierreich nicht vorkommt: eine genau parallele Entwickelung aller Arten, so folgt dies ron meinem Standpunkt aus ganz von selbst. Die einen Arten sind eben in der Phylogenese weiter rorgeschritten, als die anderen. Spencer und O. Hertwig werden diese 'Thatsache durch die Annahme erklären müssen, dass die eine Art häufiger noch Fehler macht bei der Fütternng der Larren, als die andere, dass es bei der einen Art noch öfter rorkommt, dass eine Arbeiterlarve zu unrechter Zeit zu stark gefüttert wird und dadurch dann die für meine Theorie so rerderbliche Zwischenform liefert. Ich lätte theoretisch nichts dagegen einzuwenden, insofern nach meiner Ausicht auch der Futterungsinstinkt der Arbeiterinnen sich erst allmählich so festgestellt hat, wie wir ilın heute in höchster Vollkommenheit bei den Bienen ausgebildet sehen und bei den Ameisen wohl mit Recht voraussetzen. Aber ich muss mir doch die Frage erlauben, wie die Herren es sich erklären, dass eine solche allnählich gesteigerte Ausbildung des Fütterungsinstinktes ron ihrem Standpunkt aus möglich war, da doch die Arbeiter sich nicht fortpflanzen? Sie hörten wahrseheinlich erst auf sich fortzupflanzen, als sie ihr Pensum in der Fütterungstechnik bereits vollkommen erlernt hatten; schade nur, dass durch diese Amnahme dann wieder die Erklärung des versehiedenen Verhaltens verschiedener Arten in der Häufigkeit der Hervorbringung von Zwischenformen in Wegfall kommt! Entweder alle Arten haben aufgehört sich fortzupflanzen, nachdem sie die besagte Kunst bereits vollstaindig erlernt hatten - und dann kann es bei der einen Art nicht öfter Zwischenformen geben, als bei der andern, - oder sie haben sich in den Geheimnissen der Erziehung nachher noch verrollständigt, als sie schon steril geworden waren, und damit ist nicht abzusehen, wie dies habe geschehen können, olne dass Selection des Keimplasma's der Geschlechtsthiere dabei im Spiele war. 
Gerade dies aber wird ron Spencer auf das Bestimmteste abgelehnt!

Dieselbe Argumentation passt aber auf alle Veränderungen, welche seit dem Sterilwerden der Arbeiter noeh weiter eingetreten sind, vor Allem anf die in verschiedenem Grade bei verschiedenen Arten eingetretene Reduction der Eiröhren des Arbeiterovarinms. Wir werden uberall auf Selection zurïkgewiesen.

Und was haben die Herren für eine Erklärung fii $r$ die geringe Zahl der fruchtbaren Weibchen bei Ameisen, Bienen und Termiten? Offenbar gar keine, während die von mir gegebene kaum abgelehnt werden kann. Obgleich aber Spencer sich sonst Naturzïchtung als ein Hinterpförtchen offen hält, durch welches er hinausschliupft, wenn seine sonstigen Hilfsmittel ihn im Stiche lassen, so vermag er doch in diesem Fall dieses Pförtchen nicht zu benutzen. Denn er wiirde die Richtigkeit der von mir vertheidigten 'These anerkennen, dass die Umwandlungen der Weibchen zu Arbeiterimnen auf Selection beruhen, was ja gerade der Cardinalpunkt ist, um den der ganze Kampf sich dreht. Nach meiner Auffassung verringerte sich die Zahl der einen Staat begriundenden Königinnen im Laufe der Phylogenese aus dem Grunde mehr und mehr, weil dadurch die Arbeiterimmen des Stocks mehr und melı ähnlich werden müssen, bis sie schliesslich bei den Bienen alle so ähnlich sind, als eben Kinder eines Elternpares zu sein pflegen. Es liegt auf der Hand, dass hierdurch der Process der Natur. ziichtung durch Auslese der besten Stöcke ganz ungemein gefördert wird, demn nun wird wirklich die Giite des Stockes mit der Güte des e in en Elternpares (in Bezug auf die Production bester Arbeiterimnen) zusammenfallen, wie ich dies bereits in einer früheren Arbeit ${ }^{1}$ ) und wieder im Texte dieses

1) "Die Allmacht der Naturziichtmng", eine Erwiderung an Herbert Spencer, Jena 1893. 
Vortrags ausgefuihrt habe. Der Process besteht einfach darin, dass gut veranlagte Eltern, d. h. Eltern, deren Keimplasma beste Arbeiter-Ide enthielt, dam am meisten Aussicht hatten, ihren Stock zu erhalten und in ihren Nachkommen zu iiberleben, wenn sie die einzigen Eltern des Stockes waren. Sobald noch viele andere Eltermpare demselben Stock den Ursprung gaben, komnten sich darunter anch solche befinden, deren Keimplasma minder gute Arbeiter-Ide entlielt, die also minder gute Arbeiterinnen hervorbrachten. Ein Stock aber, in dem gute und schlechte Arbeiterimnen gemischt enthalten sind, ist keine reine Selectionseinheit, wie dies Wolff seiner Zeit schom ganz richtig erkannt hatte, wemn er auch das Mittel nicht sah, durch welches Natur hier dem Besseren zum Sieg verhilft: die Reduction der Elteruzahl des Stockes.

Allerdings ist nicht bei allen staatenbildenden Insecten nur eine Königin Begriunderin des Staates, und dies kamn in verschiedener Weise gedentet werden. Es könnte eine Vorstufe der noch nicht emeichten höchsten Vollkommenheit der Einrichtung sein, es könnte aber anch ganz wohl in anderen, für uns noch nicht erkennbaren Nebenbeziehungen seinen Grund haben, z. B. in einer nicht himreichend grossen Fruchtbarkeit der Königinnen. Weitere Untersuchungen werden dariiber wohl Aufschluss geben, und es wäre wohl angebracht, wemn unsere feinen Ameisenkemner jetzt gerade dieser Frage von der Zahl der eine Kolonie begründenden Küniginnen mit Hinblick auf die übrigen Verhältnisse der betreffenden Arten noch fernerhin ihre scharfe Beobachtungsgabe zuwenden wollten. Einiges ist ja dariiber in neuester Zeit bekannt geworden, aber es muisste noch Vieles hinzugefügt werden, ehe man sicher urtheilen kömnte.

Ich habe mich bisher auf den Standpunkt meiner Gegner gestellt und einfach nur von "Zwischenformen ${ }^{\text {" }}$ zwischen Arbeiterinnen und Königimnen gesprochen, so wie diese es thun, gestiitzt vermuthlich auf die Bemerkung irgend eines referirenden Aufsatzes iiber Ameisen. Ich schreite jetzt dazu, 


\section{- $76-$}

diese sogenannten "Zwischenformen" einer etwas erusteren Prifung zu unterzielıen. Hätten meine Gegner die genauen Angaben der Specialisten über die Beschaffenheit dieser merkwïrdigen Formen zu Rathe gezogen, so wiirden sie vermutllich Anstaud genommen haben, mit iluer "Erklärung" hervorzutreten.

Forel, dem wir dariber zahlreiche, selur genaue und ins Einzelne gelıende Angaben verdanken ${ }^{1}$ ), unterscheidet scharf zwischen einfach "fruchtbaren Arbeiterinnen" und diesen "Zwischenformen". Vor seinem grossen Werk über die schweizerischen Ameisen waren iiberhaupt nur zwei Fälle von letzteren beschrieben worden: einer von Eméry an Leptanilla Revelierii und ein zweiter von Peter Huber an Polyergus rufescens beobachtete. Forel hat ihrer viele gesehen und bringt dieselben in zwei Kategorien. Die erste wird von Thieren gebildet, die in ihrer ausseren Erscheinung nur wenig von Arbeiterinnen abweichen, die aber keine verkümmerten, d. h. aus nur wenigen Eiröhren bestehenden Ovarien besitzen, wie diese, sondern zahlreiche Eiröhren, ganz wie bei der Königin. In Folge dessen ist auch iln. Hinterleib dicker und ilıre Statur etwas nutersetzter (plus trapue), als bei der Arbeiterin. Wiese Kategorie ron "Zwischenform" ist selten und ron Forel nur bei Polyergus rufescens ifters gefunden worden. Ausserdem beobachtete er sie vereinzelt bei Formica rufibarbis und ein Mal bei Myrmica rubida. In ihren Gewohnheiten verhalten sie sich insoweit wie ächte Weibchen, als sie die Experlitionen der Arbeiterimnen nicht mitmachen.

Wie sollen num diese Formen in der 'Theorie der directen Bewirkung Erklärung finden? Die Eierstöcke voll ausgebildet, der Körper aber nach Art der Arbeiterin verändert! Wenu minderwerthige Fütterung genügt, um das Ovarium zur Verkiimmerung zu bringen und dell Arbeitertypus des Körpers

1) Auguste Forel, „Fourmis de la Suisse“, Bâle, Geneve, Lyon, 1874, p. 137 и. f. 
hervorzurufen, d. h. Schwund der Flügel, Umändermug des Thorax, Verorösserung des Gehirns n. so w., welche intermediäre Fiitterungsmethode hat diese Zwischenformen hervorgerufen? Wie konnte der Körper der einer Arbeiterin werden, wïhrend doch die rolle Entwickelung der Orarien beweist, dass die Fïtterung eine könighiche war? Aber vielleicht war die Nahrung yuerst kärglich und wurde erst in späteren Stadien eine reichliche, und vielleicht wird das Aeussere der Arbeiterin früher schon bestimmt, als das Innere, oder vielleicht doch als das Ovarium! Ich kann darüber nicht entscheiden, aber unwahrseheinlich erscheint es mir schon deshalb, weil in diesem Fall solche Arbeiterinnen mit königlichem Eierstock häufig vorkommen müssten, da Unregelmässigkeiten in der Fiitterung nicht selten sein können. Sie kommen aber sehr selten vor, und wemn sonst Arbeiterinnen fruchtbar werden bei reichlicher Ernährung, so haben sie dennoch nicht den Eierstock der K̈̈nigin, sondern den nur aus 2 oder 3 Eiröhren bestehenden rudimentären Eierstock der Arbeiterin.

Von meinem Standpunkte aus erklärt sich die Sache ganz einfach. Bei den betreffenden Arten kommen noch einzelne Ide vor, die die Umwandlung zur Arbeiterin noch nicht ganz durchgemacht haben, bei welchen z. B. wohl die Determinanten der Körperform, besonders des Thorax, dem Arbeitertypus entsprechen, nicht aber die der Ovarien. Wenn es nun vorkommt, dass einmal dureh Reductionstheilung und Amphimixis ein Ei eine Mehrzahl solcher Ide zugetheilt bekommt, so wird diese Art von Zwischenform entstehen.

Die zweite Kategorie von "Zwischenformen" ist häufiger, als die erste und wurde von Forel bei mehreren Arten gefunden, bei Formica rufa, sanguinea und rufibarbis, Tapinoma nigerrimum und Myrmica laevinodis. Diese Zwischenformen haben das rudimentäre, nur aus 1-3 Eiröhren bestehende Ovarium der Arbeiterin, sind auch nicht grösser als diese, aber ihr Thorax nähert sich in seinem Bau bedeutend dem der Königinnen; er ist gross und bucklig und zeigt die 
Ansatzstiicke der Flïgel, und auch der Kopf ist klein und ähnelt dem der Königin.

Wie wäre das durch unrichtige Fiitterung der Larren nach den Ansichten Spencer's nud O. Hertwig's zu erkläiren? Da dieselben nicht grösser als Arbeiterimnen sind, wie Forel ausdrücklich betont, so können sie auch nicht mehr Futter erhalten haben, als diese; wie komnte nun trotzdem der Thorax und Kopf königlichen Bau bekommen? Das zu sagen muss ich den Herren selbst ïberlassen. Meine Erklärung ist wieder dieselbe, die ich oben schon gegeben habe: es sind Ide zur Majorität gelangt, in welchen die Determinanten der Ovarien, des Abdomen u. s. w. dem Arbeitertypus angehörten, diejenigen des Kopfes und des Thorax noch nicht stark abwichen von denen der Königinnen.

In den Angaben Forel's ist aber noch ein weiteres Noment enthalten, welches klar erkennen lässt, dass solche Zwischenformen auf einer eigenthümlichen Beschaffenheit des Keimes beruhen muissen und nicht auf irgend welchen Versehen in der Larvenfütterung, ja iiberhaupt nicht in irgend welchen äusseren Unständen. Forel fand in einem Ameisenhaufen von Formica rufa auf dem Ütliberg bei Ziirich am 1. August 1869 eine grosse Menge dieser eben besprochenen Zwischenformen der zweiten Kategorie. Sie betrugen nach seiner Schätzung: etwa ein Fünftel der ganzen Bevölkerung des Stockes. Viele davon waren sehr klein, nicht über $5 \mathrm{~mm}$ lang, und auch die grösseren erreichten nicht die gewöhnliche Grösse der Arbeiterinnen dieser Art. Er nahm einen 'I'heil dieses Nestes mit nach Hause nnd beobachtete ihn lange Zeit. Diese Zwischenformen waren stets sehr faul und schlaff, arbeiteten niemals und halfen weder am Bau des Nestes, noch bei der Fiitterung der Larven und der Versorgung der Puppen. Sie erwiesen sich als "peu intelligents", wie schon ihr kleiner Kopf erwarten liess.

Wir haben in dieser sehr interessanten Beobachtung zunächst den Beweis dafür, dass mindestens diese Art von Zwischenformen für den Stock, der sie hervorbringt, von keinem 
Vortheil, vielmehr als umnitze Verzehrer von Nachtheil sind. Soweit hat Spencer und mit ilm O. Hertwig richtig gerathen, wenn er die Zwischenformen schädlich nennt. Wenn er aber darauf hin mich ad absurdum zu führen denkt, so irrt er. Wohl beziehe ich die phyletische Entstehung der Arbeiter auf Naturziiclitung, daraus folgt aber nicht, dass auch die der unniitzen Zwischenformen auf Naturziichtung berultt, so wenig als das Vorkommen bunt gemischter Zwitterformen bei Bienen und Ameisen als eine Wirkung der Naturzichtumg betraclitet werden kann, wem man die Entstelnung des Geschlechtes ron Naturzichtung herleitet. Es ist eben einfach Folge der ungewöhnlichen Mischung activ werdender Keimesanlagen, deren Grund wir nicht kennen. Naturziichtung hat keinen Antheil an ihrem Auftreten, wird viehnehr hier sowohl, wie bei den Zwischenformen der Ameisen auf Beseitigung derselben linwirken niissen; dem sowoll solche Zwitter-, als solche Zwischenformen sind cin Nachtheil für den Stock im Kanpf ums I)asein.

Ich kann auch meinen Gegnern nicht verschweigen, dass Forel das eben erwälnte Nest ron Formica rufa rom Ütliberg in folgenden Jahr wieder untersuchte und merkwiirdigerweise wieder eine Menge solcher Zwischenformen darin faud, die frisch ausgeschliipft waren! Er schliesst daraus, dass dieser Stock sich durch Weibchen fortpflanzte, die in ihn selbst entsprungen waren. Soviel ist jedenfalls sicher, dass auch in diesem folgenden Jahre Eier in diesem Stocke gelegt worden waren, welche diesen $\mathrm{Zwischenformen} \mathrm{den} \mathrm{Ur}^{r}$ sprung gegeben hatten. Dass aber diese Thatsache keine andere Erklärung zulässt, als dass die Weibchen, welche in beiden Jahren diese Eier gelegt hatten, ihnen ein Keimplasma mitgegeben hatten, dessen Beschaffenheit - wie imuer man sie sich auch im Einzehnen ausdenken mag - die Ursache der sonderbaren Mischung ihres Körpers war, wird schwerlich bezweifelt werden kïmnen. Jedenfalls wäre es unterhaltend, wenn die Herren Herbert Spencer und Oscar Hertwig sich dem Versuch widmen wollten, diese Mischung der 
Charaktere durch Fehler in der Fiitterung der Larven zu erklïren. Es wird interessant sein, Anfschlnss darüber zu erhalten, wieso die minderwerthige Fiitterung, die hier offenbar stattgefunden hat, wie die abnorme Kleinheit und die rudimentären Ovarien der Zwischenformen beweisen, zugleich doch den Kopf und Thorax einer Königin hervorruten komnte. Noch interessanter aber wird es sein, zu erfahren, wie die falsche Methode der Fiitternng sich iiber ein Fïnftel sämmtlicher Arbeiterimnen eines Stockes erstrecken konnte und in zwei aufeinander folgenden Jahren. Man hat noch niemals bemerkt, dass es Ameisen an Fntter fiir ihre Larven gebrochen hätte; sie fressen so Vielerlei, dass sie selten in Mangel gerathen. Anch meldet Forel Nichts davon, dass die übrigen Kolonien ron Formica rufa auf dem Ütliberg ebenfalls diese Zwischenformen enthalten hätten, er spricht vielmelır ausdriicklich nur ron e in e m bestimmten der jedenfalls zahlreich dort vorhanden Nester. Es muss also wohl eine förmliche Epidemie der falschen Brntpflege unter diesem Stock ansgebrochen sein! 



